\title{
Should a retailer sell its own extended warranties or resell those from the manufacturer when confronting supplier encroachment?
}

\author{
Junwu Chai ${ }^{\mathrm{a}}$, Hengyu Li ${ }^{\mathrm{a}}$, Wei Yan ${ }^{\mathrm{a}}$ and Youwei $\mathrm{Li}^{\mathrm{b}}$

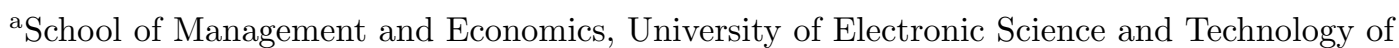 \\ China, Chengdu, China; ${ }^{\mathrm{b}}$ The Business School, University of Hull, Hull, UK
}

\author{
ARTICLE HISTORY \\ Compiled April 7, 2020
}

\begin{abstract}
Due to fierce competition in the product market under conditions of supplier encroachment, many brand name retailers, including Sears, Best Buy, and Circuit City, depend on the extended warranty contracts that they sell along with the products. The distribution of extended warranties through an intermediary can be characterized in terms of two basic forms. A large proportion of retailers sell their own extended warranty, whilst others choose to resell the extended warranty provided by upstream agents. Several questions arise from these conditions. How will optimum decisions vary under different strategic choice? Is it profitable for a retailer to engage in selling extended warranties? And finally, which strategy is more profitable for related players? We answer these questions using a game theoretic model where the retailer has the flexibility to choose between offering its own extended warranties (Model ER) or reselling extended warranties provided by a manufacturer (Model EM). Our analysis reveals that it is indeed a profitable business for both parties when the retailer engages in selling extended warranty, irrespective of whether they are owned by the retailer or by the manufacturer. Surprisingly, we find that, when marketing cost of the extended warranty is high, the retailer benefits more from reselling the extended warranty, a strategy that is always beneficial for the manufacturer. Put differently, when marketing cost of the extended warranty is high, reselling extended warranties from the manufacturer can secure Pareto improvements. However, when marketing cost of the extended warranty is not pronounced, a preference confliction arises between both parties: The retailer prefers to sell its own extended warranty, while the manufacturer would be fond of the other one. Extending both models to the case where the manufacturer encroaches into retail market with selling both products and extended warranty reveals that the preference confliction between both parties is quite robust.
\end{abstract}

\section{KEYWORDS}

Supply chain; E-commerce; Supplier encroachment; Extended warranty; Game theory

\section{Introduction}

Manufacturers have competed with retailers for the loyalty of consumers by selling products directly for many years, which is often referred to as "supplier encroachment" (Arya et al. 2007). Numerous examples of supplier encroachment can be observed in a variety of industries, such as electronics, appliances, sporting goods, and apparel 
(see, e.g., Tedeschi (2000); Xiong et al. (2012)). This trend tends to change traditional supply chains into dual-channel supply chains and can threaten the profitability of existing retailers (Yan et al. 2017). Cattani et al. (2006) has used the parable of the boiling frog to illustrate that the manufacturer will "boil" the traditional retailer who adheres to a more convenient direct-based distribution channel.

Retailers have adopted various ways to confront supplier encroachment and expand their profit space beyond selling products. Many retailers, including Sears, Best Buy, and Circuit City, depend on the extended warranty contracts that they sell along with the products. "Some of the largest electronic and appliance retailers would be losing money if it weren't for the profits they make from selling [extended] warranties" (Pingle 2010). Extended warranties offer retailers $44-70 \%$ of the profit margins, which is nearly eighteen times the typical margin on product sales, and far exceeds the margin on the sale of a product itself (Berner 2004). Today, extended warranty plans are available for almost all durable goods sold in retail stores, from bicycles to wedding jewelry, and so pervasive that it is rare to find a major retailer in the U.S that does not offer them (Jiang and Zhang 2011).

Extended warranties differ from the manufacturer's basic warranty that comes bundled with the product; they are optional insurance products that require consumers to pay premiums upfront for additional coverage after the manufacturer's basic warranty expires. An extended warranty provides consumers with "peace of mind" about failures of the product after the basic warranty expires. Offering an extended warranty works for firms as a mechanism for price discrimination with consumers who self-select into an appropriate warranty plan (Chu and Chintagunta 2009), and also provides an opportunity to build and maintain a relationship with the consumer (Hartman and Kamonkan 2010). As a result, manufacturers have adopted various measures to ask retailers to commit to selling their extended warranty exclusively. For example, Ford of Canada announced that, as a condition for the use of its financing plan, dealers had to commit to exclusive sales of their extended warranty program (Hollis 1999).

Hence, the question arises: Should a retailer sell its own extended warranties or resell those from the manufacturer when confronting supplier encroachment? Put differently, the issues for a manager have to focus on the implications of the retailer's strategic response with offering extended warranties as follows: How will optimum decisions vary under different strategic choice? Is it profitable for a retailer to engage in selling extended warranties? And finally, which strategy is more profitable for the related parties, e.g., the manufacturer and retailer, to sell retailer's own extended warranties or resell those provided by the manufacturer?

Although several authors, including Desai and Padmanabhan (2004), Li et al. (2012), and Mai et al. (2017), have addressed the design of extended warranty given the structure of different supply chains, they have not paid attention to how supplier encroachment affects the strategic choices involved in offering extended warranties. On the other hand, although supplier encroachment has been well studied (see, e.g., Arya et al. (2007), Xiong et al. (2012), Ha et al. (2016) and Yu et al. (2019)), current research focuses primarily on products marketing in dual-channel supply chains. To the best of our knowledge, neither the role of extended warranty under supplier encroachment nor the issue of marketing products with an optional extended warranty in a dual-channel setting has been explored in the literature.

This paper presents the two stylized theoretical models that we developed to address the preceding questions. More specifically, we have focused on the situation where a manufacturer sells products through a direct channel, as well as an independent retailer, and where a retailer can choose between selling its own extended warranty 


\section{Literature Review}

This research relates to literature on the extended warranty design. Particularly, Jiang and Zhang (2011) have studied the impact of a retailer's extended warranty on the manufacturer's underlying warranty policies and channel performance and found that the provision of an extended warranty always increases profits for retailers and the entire supply chain. Subsequently, Heese (2012) has considered the interactions between two competing manufacturers who sold their products through a single independent retailer, who also sold extended warranties. Considering the emerging influence of network externality on supply chain, Tan et al. (2015) then studied retailer-leading supply chain coordination with the extended warranty and found network externality exacerbated the efficiency loss of decision making. Recently, Zheng et al. (2018) developed theoretical models regarding selling flexible extended warranty, and they find that flexible warranty is always superior to the traditional extended warranty when the cost efficiency of warranty is relatively high and/or the length of warranty is relatively short. More recently, Lu and Shang (2019) proposed a model to describe the relationship between independent third-party warranty providers and e-tailers, and found e-tailers can motivate the inspection efforts of third-party warranty providers by an profit-sharing plan. Meanwhile, Bian et al. (2019) investigated the selection strategy between traditional extended warranty and innovate trade-in extended warranty under different failure probabilities. In spite the fact the discussion about extended warranties in the aforementioned studies are with respect to competition, consumer behavior and many aspects, however, they do not address the impact of manufacturer's encroachment on retailer's optimal extended warranties strategy.

Recently, an increasing number of researchers have studied the design and pricing strategies with respect to extended warranties. For example, Desai and Padmanabhan (2004) studied the problem of coordinating channels when offering a manufacturer's extended warranty and found that it is best for manufacturers to choose dual-channel, 
and for third parties to sell through retailers. Li et al. (2012) have developed several game-theoretical models to compare different designs for extended warranties in a supply chain context with a manufacturer, a retailer, and a third-party (who provides the extended warranty). Ma et al. (2019) found that the interaction forces of supply chain competition and extended warranty service significantly impact the characteristics of the equilibria, and designed a two-part tariff contract to results in a win-win solution for supply chain members. Zhou et al. (2019) studied firms' reliability and extended warranty pricing decisions in different supply chain structures. Zhang et al. (2019) investigated the influence of service cost on the choice of the extended warranty provider. They show that if only limited consumers purchase the extended warranty and suitable ratio of service cost coefficient, the manufacturer benefits from extended warranty provided by the retailer. However, this literature has not considered the design of extended warranty design in conditions of supplier encroachment. We provide an alternative, yet somewhat complementary approach, by addressing how supplier encroachment affects the optimal strategy available to retailers when marketing extended warranty.

Our paper also contributes to the literature on encroachment. In the mid-1990s, Frazier and Lassar (1996) reported that supplier encroachment can decrease the efforts of a retailer to sell a product and also dilute brand image. In a more contemporary context, Chiang et al. (2003) have demonstrated that when a supplier threatens to sell through a direct channel, retailers will lower the selling price, which can benefit both the supplier and retailer. Likewise, Cattani et al. (2006) have shown that supplier encroachment is not necessarily detrimental to the retailer and can benefit both the supplier and the retailer, if the supplier commits to equal-pricing. Arya et al. (2007) have provided further insights by showing that the direct sale of an encroaching manufacturer not only adds another source of profit but can motivate them to offer a lower wholesale price to maintain demand from the retailer's channel. Recently, Yu et al. (2019), assuming consumer channel preference between the direct and indirect channels, investigated a manufacturer's encroachment decision in a shopping complex with the choices for the indirect channel being reselling and agency selling. Similarly, Tsay and Agrawal (2004), Xiong et al. (2012), Yan et al. (2017) and Cao et al. (2019) examine several ways to adjust the both partners' relationship and conclude that the introduction of a supplier direct channel can still benefit both partners. Our work differs from this research because besides focusing on the competition between the upstream agent (the manufacturer) and the downstream agent (the retailer) when distributing products, we also pay attention to the strategic response of retailers in marketing extended warranties. Moreover, we focus on the specific condition where the retailer has the flexibility to choose between distributing its own extended warranty or that offered by the manufacturer.

\section{Model Development}

This section introduces our notation and lay out our assumptions regarding the cost, demand functions, and then reanalyzes a benchmark case where the retailer and the manufacturer distribute products only. The timing in all models is as follows. First, the manufacturer announces its wholesale prices and the optimal extended warranty length $\left(w_{p}, w_{e}\right.$ and $\left.t\right)$ for products and/or extended warranties (we use $w_{i j}^{k}$ refers to the wholesale price for product $j$ sold by the player $i$, where subscript $i \in\{r, m\}$ denotes the manufacturer, the retailer, respectively, and $j \in\{p, e\}$ denotes the prod- 
uct, the extended warranty, respectively). While, superscript $K \in\{E N, E R, E M\}$ denotes Model EN, ER and EM, respectively. Second, the retailer chooses its profitmaximizing retail units of products $\left(q_{r p}\right)$, selling price of extended warranties $\left(p_{e}\right)$ and the optimal extended warranty length of $(t)$. Finally, the manufacturer determines the number of units $\left(q_{m p}\right)$ of the homogeneous products that they will encroach into the retailer's market. (In our both models, all customers purchase the the extended warranty only from the retailer channel, we would relax this assumption in $\S 5$. We thank an anonymous reviewer for providing such a constructive suggestion on extension.)

\subsection{The Costs}

Following Arya et al. (2007), we normalize the unit (marginal) cost for producing a product to zero, assume that the marginal cost of selling products through a manufacturer-owned direct channel is $c>0$, and that the marketing cost of a unit in the traditional retail channel is zero. These assumptions are common in literature regarding the dual-channel supply chain (e.g., Arya et al. (2007); Xiong et al. (2012) and $\mathrm{Li}$ et al. (2014)) and reflect that the retailer is considered an incumbent who has the ability to deter entry to the manufacturer (Lutz 1997). We also assume a quadratic cost, $\frac{k t^{2}}{2}$, that depends on the length of the extended warranty. This assumption is consistent with findings in the literature that the number of product failures increases exponentially over time (e.g., Anderson (1977) and Patankar and Worm (1981)).

\subsection{Demand Functions}

Two demand functions are derived in our analysis, the demand for the product and for the extended warranty (e.g., Desai and Padmanabhan (2004); Heese (2012); Li et al. (2012)). A product demand function of $p=1-q$ is determined, where $p$ is the market clearing price and $q$ is the total quantity of the product that includes the units sold by the retailer $\left(q_{r p}\right)$ and the manufacturer $\left(q_{m p}\right)$; that is, $p=1-q_{r p}-q_{m p}$. Only those customers who buy the product are considered potential customers for the extended warranty and, thus, demand for the extended warranty is limited by product demand. Following Li et al. (2012), we let $p_{e}$ refers to the price of extended warranty and $t$ represents the length of the extended warranty. Letting $d \in(0,1]$ denote the price sensitivity of the extended warranty, then, as also identified by Desai and Padmanabhan (2004) and Li et al. (2012), the demand for the extended warranty is $q_{e}=q_{r p}+q_{m p}-d p_{e}+t$. Such assumption reflects that fact that, confronting a menu of extended warranties, consumers usually considers both price and duration of coverage. That is, the extended warranty demand $q_{r e}$ should be decreasing in extended warranty price $p_{e}$ and increasing in extended warranty length $t$.

All description of notations are listed in Table 1.

\subsection{Model ER}

In Model ER, the manufacturer sells product through a direct channel, as well as an independent retailer who offers its own extended warranty. As such, in the first stage, the manufacturer's problem is:

$$
\underset{w_{p}}{\operatorname{Max}} \pi_{m}^{E R}=w_{p} q_{r p}+(p-c) q_{m p}
$$


Table 1. Description of notations.

\begin{tabular}{ll}
\hline Symbol & Description \\
\hline Variables & \\
\hline$w_{p}^{K}$ & The wholesale price of product under Model $K$. \\
$w_{e}^{K}$ & The wholesale price of extended warranty under Model $K$. \\
$p^{K}$ & The selling price of product under Model $K$. \\
$p_{e}^{K}$ & The selling price of extended warranty under Model $K$. \\
$q_{r p}^{K}$ & Quantities of products from retail channel under Model $K$. \\
$q_{m p}^{K}$ & Quantities of products from direct channel under Model $K$. \\
$t^{K}$ & The length of the extended warranty under Model $K$. \\
\hline Parameters & \\
\hline$K \in\{E R, E M\}$ & The superscript denotes the outcomes of Model $E R$ and Model $E M$. \\
$d$ & The price sensitivity of the extended warranty. \\
$c$ & The marginal cost of selling product through direct channel. \\
$k$ & Cost efficiency of investment on extended warranty. \\
$\pi_{r}^{K}$ & The profits for retailer under Model $K$. \\
$\pi_{m}^{K}$ & The profits for manufacturer under Model $K$. \\
$*$ & The equilibrium results of decision variables. \\
\hline
\end{tabular}

where the first term is the revenue from products wholesaling, while the second term is the revenue from supplier encroachment.

Given the manufacturer's wholesale price $w_{p}$, then at the second stage, the retailer's problem is:

$$
\underset{q_{r p}, p_{e}, t}{\operatorname{Max}} \pi_{r}^{E R}=\left(p-w_{p}\right) q_{r p}+\left(p_{e}-\frac{k t^{2}}{2}\right)\left(q_{r p}+q_{m p}-d p_{e}+t\right)
$$

In the last stage, the manufacturer would encroach into the retail market by choosing $q_{m p}^{E R^{*}}$, that is:

$$
\underset{q_{m p}}{\operatorname{Max}} \pi_{m}^{E R}=w_{p} q_{r p}+(p-c) q_{m p}
$$

Using backward induction, the equilibrium decisions and profits for the channel partners in Model ER are given in Table 2.

\subsection{Model EM}

We now consider Model EM involves supplier encroachment into a retail market where the retailer resells the extended warranty wholesaled by the manufacturer. As such, the manufacturer's problems is:

$$
\underset{w_{p}, w_{e}, t}{\operatorname{Max}} \pi_{m}^{E M}=w_{p} q_{r p}+\left(q_{r p}+q_{m p}-d p_{e}+t\right)\left(w_{e}-\frac{k t^{2}}{2}\right)+\left(1-q_{r p}-q_{m p}-c\right) q_{m p}
$$

where the first two terms are the revenues from products and extended warranty wholesaling, the last term is the revenue from supplier encroachment.

Given the manufacturer's wholesale prices $w_{p}$ and $w_{e}$, and anticipating the manufacturer's response $q_{m p}$, at the second stage, the retailer's problem is:

$$
\underset{q_{r p}, p_{e}}{M a x} \pi_{r}^{E M}=\left(1-q_{r p}-q_{m p}-w_{p}\right) q_{r p}+\left(p_{e}-w_{e}\right)\left(q_{r p}+q_{m p}-d p_{e}+t\right)
$$


Table 2. Equilibrium Decisions and Profits

\begin{tabular}{|c|c|}
\hline Equilibrium Decisions and Profits in Model ER & Equilibrium Decisions and Profits in Model EM \\
\hline$w_{p}^{E R^{*}}=\frac{d k-4 d+4 d^{2} k-48 d^{3} k-c d k+4 c d^{2} k+16 c d^{3} k+1}{16 d^{2} k(1-6 d)}$ & $\left.\begin{array}{l}2 d k-6 d-14 d^{2} k+44 d^{3} k-96 d^{4} k+12 d^{2} \\
-2 c d k+18 c d^{2} k-44 c d^{3} k+32 c d^{4} k+1 \\
64 k d^{3}-192 k d^{4}-16 k d^{2}+2 k d \\
10 d+2 d^{2} k-16 d^{3} k+48 d^{4} k-48 d^{2} \\
+144 d^{3}-2 c d^{2} k+32 c d^{3} k-112 c d^{4} k-1\end{array}\right]$ \\
\hline $\begin{array}{l}q_{r p}^{E R^{*}}=\frac{d k-c d k+8 c d^{2} k+1}{2 d k(6 d-1)} \\
t^{E R^{*}}=\frac{1}{d k}\end{array}$ & $\begin{array}{rl}w_{e} & 2 d^{2} k\left(96 d^{3}-32 d^{2}+8 d-1\right) \\
q_{r p}^{E M^{*}} & =\frac{2 d k-2 c d k+64 c d^{3} k+2}{k\left(96 d^{3}-32 d^{2}+8 d-1\right)} \\
t^{E M^{*}} & =\frac{1}{d k} \\
& {\left[6 d-2 d k+14 d^{2} k-56 d^{3} k+96 d^{4} k\right.}\end{array}$ \\
\hline$p^{E R^{*}}=\frac{3 d k-12 d^{2} k+c d k-4 c d^{2} k+1}{4 d k(1-6 d)}$ & $p^{E M^{*}=} \frac{\left[-24 d^{2}-6 c d^{2} k+24 c d^{3} k+32 c d^{4} k-1\right.}{2 d k\left(96 d^{3}-32 d^{2}+8 d-1\right)}$ \\
\hline $\begin{array}{l}p_{e}^{E R^{*}}=\frac{36 d-d k+12 d^{2} k+c d k-4 c d^{2} k-5}{8 d^{2} k(6 d-1)} \\
g^{E R^{*}}=\frac{3 d k-12 d^{2} k-3 c d k+20 c d^{2} k+1}{2-11}(1)\end{array}$ & 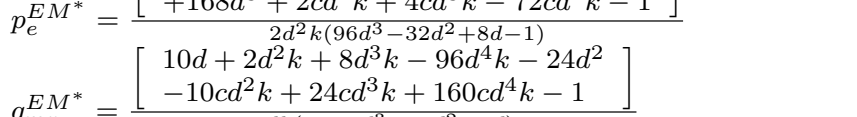 \\
\hline$\left[\begin{array}{c}4 d k(1-6 d) \\
112 c^{2} d^{4} k^{2}-24 c^{2} d^{3} k^{2}+c^{2} d^{2} k^{2}-96 c d^{4} k^{2} \\
+32 c d^{3} k^{2}-2 c d^{2} k^{2}+16 c d^{2} k-2 c d k \\
+48 d^{4} k^{2}-8 d^{3} k^{2}+d^{2} k^{2}+2 d k+1\end{array}\right.$ & $\left.\begin{array}{l}2 d k\left(1-96 d^{3}+32 d^{2}-8 d\right) \\
224 c^{2} d^{5} k^{2}-20 c^{2} d^{4} k^{2}-4 c^{2} d^{3} k^{2}-192 c d^{5} k^{2}-4 d \\
+40 c d^{4} k^{2}-24 c d^{3} k+16 c d^{2} k-2 c d k+96 d^{5} k^{2}+1 \\
-20 d^{4} k^{2}+4 d^{3} k^{2}+24 d^{3} k-8 d^{2} k+12 d^{2}+2 d k\end{array}\right]$ \\
\hline $\begin{array}{l}\pi_{m}^{\nu 1}=\frac{32 d^{3} k^{2}(6 d-1)}{} \\
\pi_{r}^{E R^{*}}=\frac{\left[\begin{array}{l}512 c^{2} d^{5} k^{2}-48 c^{2} d^{4} k^{2}-24 c^{2} d^{3} k^{2}+3 c^{2} d^{2} k^{2} \\
-160 c d^{4} k^{2}+64 c d^{3} k^{2}-160 c d^{3} k-6 c d^{2} k^{2} \\
+64 c d^{2} k-6 c d k+144 d^{4} k^{2}-40 d^{3} k^{2}+288 d^{3} k \\
+3 d^{2} k^{2}-80 d^{2} k+144 d^{2}+6 d k-40 d+3\end{array}\right.}{64 d^{3} k^{2}(6 d-1)^{2}}\end{array}$ & 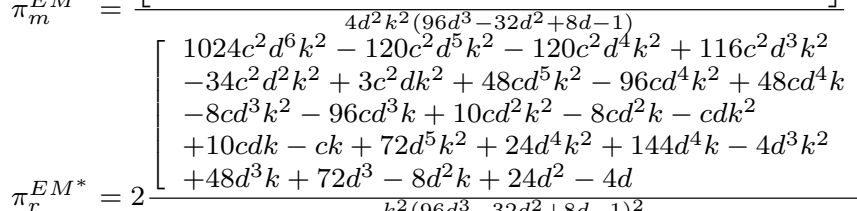 \\
\hline
\end{tabular}
ing:

In the last stage, the manufacturer would encroach into the retail market by choos-

$$
\underset{q_{m p}}{\operatorname{Max}} \pi_{m}^{E M}=w_{p} q_{r p}+\left(q_{r p}+q_{m p}-d p_{e}+t\right)\left(w_{e}-\frac{k t^{2}}{2}\right)+(p-c) q_{m p}
$$

Using backward induction again, we can obtain the equilibrium decisions and profits for the channel partners in Model EM, which are given in Table 2.

\section{Analysis}

\subsection{What Are Implications?}

To gain a deeper understanding for the subsequent research questions, we go the first step to compare the optimal decisions of both parties in Model EM with those in Model ER. That is, as shown in Figure 1, we can construct the following proposition on how will optimum decisions vary under different strategic choice?

Proposition 1. (i) In Model EM, if $k<k_{1}$, the manufacturer sets a lower wholesale price for the product than that in Model ER (i.e. $w_{p}^{E M^{*}}<w_{p}^{E R^{*}}$ in Figure 1(a)); otherwise, the opposite is true.

(ii) In Model EM, if $k<k_{1}$, the manufacturer sells more units through the direct channel (i.e., $q_{m p}^{E M^{*}}>q_{m p}^{E R^{*}}$ in Figure 1(c)), but makes less units available in the traditional retail channel (i.e., $q_{r p}^{E M^{*}}<q_{r p}^{E R^{*}}$ in Figure 1(b)); otherwise, the opposite is true.

(iii) The extended warranty coverage in Model EM is equal to that in Model ER 
(i.e., $t^{E M^{*}}=t^{E R^{*}}$ ).

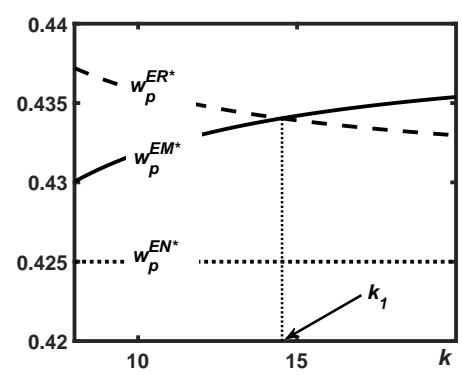

(a) The optimal wholesaling price.
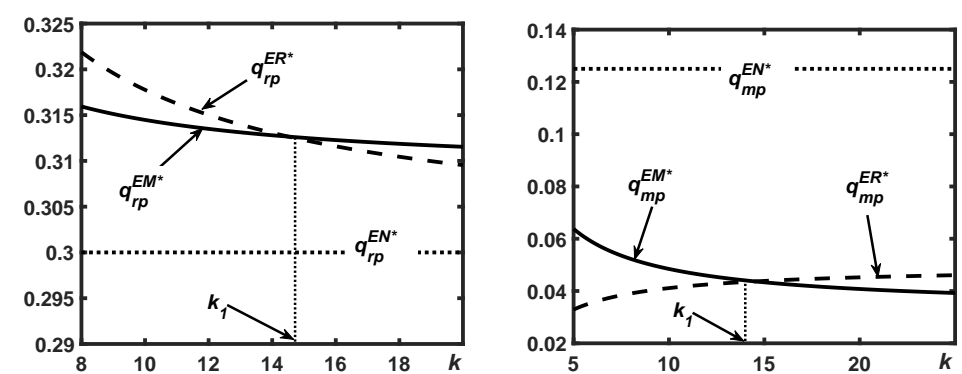

(b) The optimal sales volume in retail(c) The optimal sales volume in direct channel. channel.

Figure 1. The optimal outcomes of both parties (Note, in this example, $d=0.8, c=0.45$ )

Proposition 1 (i) reveals that, if $k<k_{1}$, confronting the retailer resells its own extended warranty, the manufacturer would charge a higher wholesale price for the product. Note that, when $k<k_{1}$, meaning that the cost of providing extended warranty is quite low, it is profitable for offering the extended warranty. Confronting an increase in the retailer's profit from selling extend warranty, the manufacturer would charge a higher wholesale price to leverage this potential to create value for itself. On the other hand, when $k>k_{1}$, meaning that the cost of providing extended warranty is high, offering the extended warranty is not a profitable business, as such the manufacturer has no choice but set a higher wholesale price for product to maximize its profitability.

Proposition 1 (ii) shows that, if $k<k_{1}$, the manufacturer would offers more products in Model EM than that in Model ER. This can be interpreted as follows. The more products sold through the manufacturer-owned direct channel, the retailer's potential profits from selling products decreases, as such the incentives for the retailer resells the extended warranty wholesaled by the manufacturer increases. As a result, the higher quantities of $q_{m p}^{E M^{*}}$ not only directly induce the profit from selling products increases, but indirectly results in the profits from wholesaling extended warranty increases. Recalled that, only those customers who buy the product are potential customers for the extended warranty. Proposition 1 (ii) further indicates that, if $k<k_{1}$, the retailer would offers less products in Model EM than that in Model ER, due to the fiercer competition from the supplier encroachment in Model EM than that in Model ER, i.e., $q_{m p}^{E M^{*}}>q_{m p}^{E R^{*}}$.

Proposition 1 (iii) shows that, the extended warranty coverage in Model EM is always equal to that in Model ER. In other words, the decision of extended warranty 
is quite robust; they remain unchanged irrespective of whether the extend warranty are distributed by the retailer or the manufacturer. Such argument partly consistent with that in Desai and Padmanabhan (2004): Significant manufacturers commonly use the extended warranty as a segmentation mechanism involves a heavy investment in quality (Padmanabhan 1995). Hence, it is a longer term decision than the other decisions, such as pricing, inventory, promoting etc..

\subsection{Is It Profitable?}

Given the above analysis, we can now address the second question posed at the beginning of this paper: Is it a profitable business for a retailer to engage in selling extended warranties? To answer this question, we need compare the our two models' results with Arya et al.'s (2007) encroachment setting where the manufacturer sells the product directly to consumers to compete with the incumbent retailer who distributes products only. We summarize our findings in the following proposition. (Using superscript EN to represent the results from the supplier encroachment scenario in Arya et al. (2007).)

Proposition 2. Relative to competition in the product market, both parties benefit from the retailer's strategy of selling extended warranties, whether it is provided by retailer own or the manufacturer, i.e., $\pi_{r}^{E R^{*}}\left(\pi_{r}^{E M^{*}}\right)>\pi_{r}^{E N^{*}}, \pi_{m}^{E R^{*}}\left(\pi_{m}^{E M^{*}}\right)>\pi_{m}^{E N^{*}}$ in Figure 2.

Intuitively, selling extended warranty would appear to be a profitable choice for retailers, as they would receive extra profits from doing so. Consequently, many retailers prompt consumers to take extended warranties into consideration when choosing products. For example, price labels at Best Buy contain a section labeled "Don't Forget" that explicitly recommends consumers to consider extended warranties, a recommendation which is also often supported by interventions from customer sales representatives (Heese 2012).

However, Proposition 2 further shows that allowing the retailer to sell its own extended warranty also leads a higher profit for the manufacturer. To explain Proposition 2 , we go a deeper step to reveal all possible sources of manufacturer's profitability. We summarize them in the following remark.

Remark 1. Compared to competition in the product market, allowing retailer sells an additional extended warranty,

(i) creates a higher profitability for the retailer from selling extended warranty (i.e., $\left.\pi_{r e}^{E R^{*}}\left(\pi_{r e}^{E M^{*}}\right)>\pi_{r e}^{E N^{*}}\right)$, but a lower from selling products $\left(\pi_{r p}^{E R^{*}}\left(\pi_{r p}^{E M^{*}}\right)<\pi_{r p}^{E N^{*}}\right)$, in Figure 2(b), (d),

(ii) and, induces higher profits for the manufacturer from products and extended warranty wholesaling (i.e., $\pi_{m e}^{E M^{*}}>\pi_{m e}^{E N^{*}}$, and $\pi_{m p}^{E R^{*}}\left(\pi_{m p}^{E M^{*}}\right)>\pi_{m p}^{E N^{*}}$ ) in Figure 2(a), (c).

Proposition 2 revealed that both parties benefit from the retailer's strategy of selling extended warranties, Remark 1 (i), further, indicates a more nuanced understanding of supplier encroachment: Although supplier encroachment induces the retailer suffers a loss in selling products, i.e., $\pi_{r p}^{E R^{*}}\left(\pi_{r p}^{E M^{*}}\right)<\pi_{r p}^{E N^{*}}$, the retailer would expand its profit space from selling extended warranty, i.e., $\pi_{r e}^{E R^{*}}\left(\pi_{r e}^{E M^{*}}\right)>\pi_{r e}^{E N^{*}}$. In particular, although the manufacturer charges higher wholesale prices to the retailer (i.e., as Proposition 1 (i) shown, $w_{p}^{E N^{*}}<w_{p}^{E M^{*}}\left(w_{p}^{E R^{*}}\right)$ in Figure $\left.1(\mathrm{a})\right)$, the retailer would 


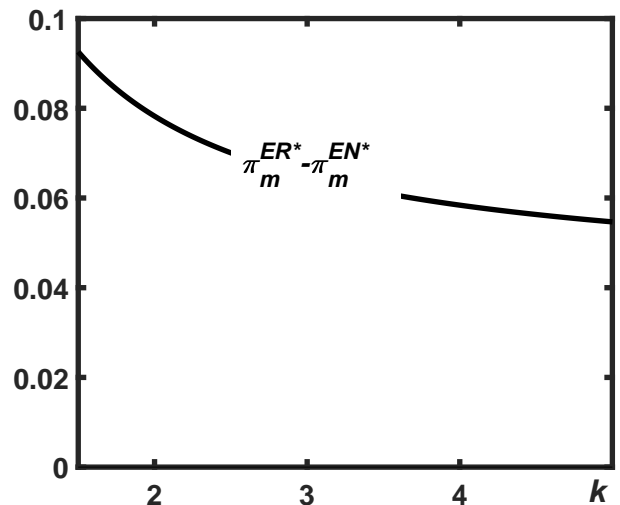

(a) The manufacturer's profits in Model ER vs. Model EN.

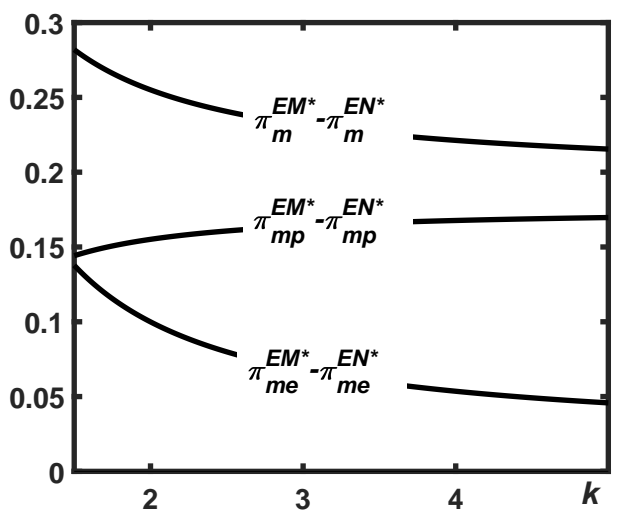

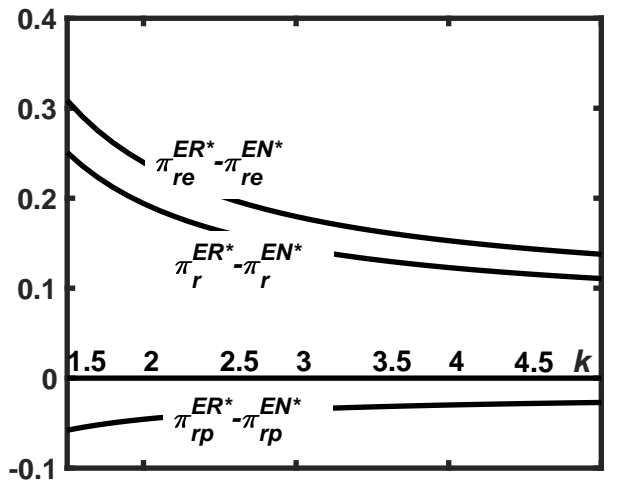

(b) The retailer's profits in Model ER vs. Model EN.

(c) The manufacturer's profits in Model EM vs. Model(d) The retailer's profits in Model EM vs. Model EN. EN.

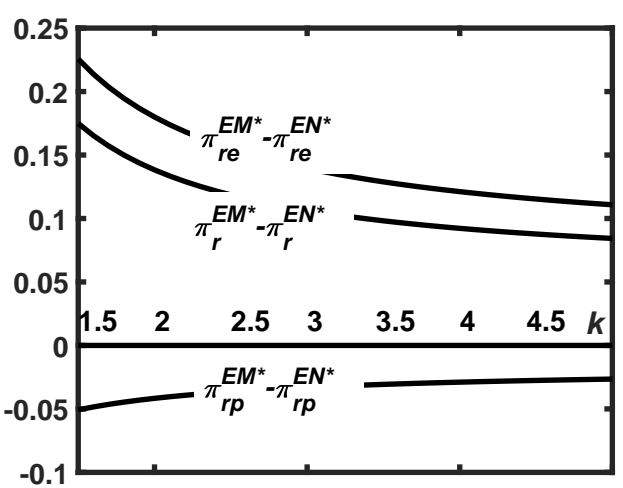

Figure 2. The profits in Model ER(EM) vs. Model EN (Note, in this example, $d=0.8, c=0.45$ )

selling more products to expand its profit space from selling extended warranty (i.e., as Proposition 1 (ii) shown, $q_{r p}^{E N^{*}}<q_{r p}^{E M^{*}}\left(q_{r p}^{E R^{*}}\right)$ in Figure 1(b)). This situation occurs for two reasons. First, given that only those customers who buy the product from the retailer are potential customers for the extended warranty, then selling more units means more potential customers who may purchase the extended warranty. Second, selling more units in the retail channel is an effective defense for supplier encroachment. More specifically, increasing the units sold through the retail channel reduces the manufacturer's potential market and marginal revenue in the direct channel. As a result, the retailer's sales volume of products is much higher than a wholesale price premium charged by the manufacturer.

Remark 1 (ii) reveals that, when the retailer sells an additional extended warranty, supplier encroachment induces higher profitability from product and extended warranty wholesaling, that is, $\pi_{m e}^{E M^{*}}>\pi_{m e}^{E N^{*}}$, and $\pi_{m p}^{E R^{*}}\left(\pi_{m p}^{E M^{*}}\right)>\pi_{m p}^{E N^{*}}$. We can interpret it as follows. We implicitly assume that the manufacturer is the Stackelberg leader in Model ER. As the manufacturer is contractually committed to retail distribution, the response of the retailer can affect profitability. As discussed earlier, the retailer would be likely to sell more units in the traditional retail channel when it sells its own extended warranty. Furthermore, increasing the units sold through the retail channel 
(i.e., $q_{r p}^{E M}\left(q_{r p}^{E R}\right)>q_{r p}^{E N}$ in Figure $\left.1(\mathrm{~b})\right)$ means that the manufacturer's potential market and marginal revenue in the direct channel decreases. As a result, compared to Model EN, the manufacturer is worse off in its own direct channel under scenario of Model ER and EM. On the other hand, the larger quantities of products sold by the retailer leads to a higher profit from product wholesaling that accompanies a higher wholesale price set by the manufacturer (i.e., $w_{p}^{E M^{*}}\left(w_{p}^{E R^{*}}\right)>w_{p}^{E N^{*}}$ in Figure $\left.1(\mathrm{a})\right)$, and it is this situation that Model $\operatorname{EM}(\mathrm{ER})$ is more dominant.

Hence, as Proposition 2 shows, compared to Arya et al.'s (2007) encroachment setting, allowing the retailer to sell its own extended warranty also leads to a higher profit for the manufacturer. In other words, when the retailer sells its own extended warranty, both parties benefit, which can secure Pareto improvements. This observation, differs from those of Cattani et al. (2006); Arya et al. (2007) and Cai (2010) because, we believe, our analysis focuses upon the potential benefits when the retailer is given the flexibility to sell its own extended warranty rather than on whether the supplier encroaches into the retail market or not.

\subsection{Which Is Better?}

In the analysis thus far, we have addressed the implications on optimum outcomes and found that it is profitable for both parties, when the retailer sells its owned extended warranties or when it resells those wholesaled by the manufacturer. One remaining questions still need addressing: Which strategy is more profitable for related parties, e.g., the manufacturer and retailer, to sell the retailer's own extended warranties or to resell those provided by the manufacturer?

Comparing the profitability in Model EM with those in Model ER, we first answer the above question from the manufacturer's perspective as follows.

Proposition 3. Compared to selling retailer's owned extended warranty, allowing the retailer to resell the manufacturer's extended warranty is always beneficial for manufacturer (i.e., $\pi_{m}^{E M^{*}}>\pi_{m}^{E R^{*}}$ in Figure 3.)

Proposition 3 indicates that, compared to when the retailer sells its owned extended warranty, allowing it to resell the extended warranty provided by the manufacturer can create a higher profitability for the manufacturer. Compared to Model ER, the manufacturer can obtain the additional revenue stream by providing extended warranty to retailer in Model EM. Intuitively, Model EM increases the manufacturer's profitability, one would expect the manufacturer would decrease the products wholesale profit by supporting the retailer's preference of reselling the extended warranty. To test this conventional wisdom, we need go a further step to figure out the deeper reasons for Proposition 3. More specifically, like Remark 1, we compare the profitability between Model EM and Model ER from two different perspectives: The profitability from products and extended warranties wholesaling (see, Figure 3).

Remark 2. Compared to Model ER, the manufacturer obtains a lower profitability from product marketing (i.e., $\pi_{m p}^{E M^{*}}<\pi_{m p}^{E R^{*}}$ ), while a higher from extended warranty (i.e., $\pi_{m e}^{E M^{*}}>\pi_{m e}^{E R^{*}}$ ) in Figure 3.

Recall that when the retailer has the flexibility of selling its owned extend warranties or reselling extended warranties provided the manufacturer, the manufacturer relies more on quantities in direct channel to control the retailer's demand and uses it more aggressively to extract profit from the retailer channel from product and extended 


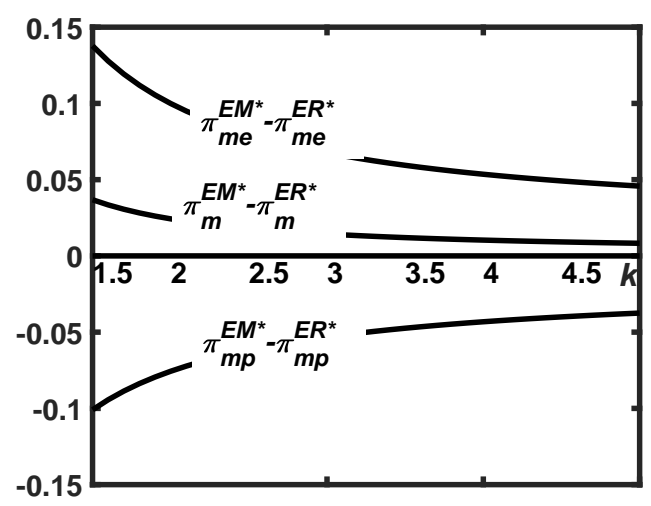

Figure 3. The manufacturer's profits in Model EM vs. Model ER (Note, in this example, $d=0.8, c=0.45$ ).

warranty. Such behavior would induce two contrary effects: On the one hand, if $k<$ $k_{1}$, the more quantities sold through direct channel, the less units available in the traditional retail channel (See, Proposition 1(ii)). The profits from direct selling can not compensate the loss from products wholesaling, because, when $k<k_{1}$, meaning selling extended warranty is a profitable business, the retailer relies more on selling extended warranty, but less on distributing products. On the other hand, if $k>k_{1}$, meaning selling extended warranty is a less profitable business, the competition between both parties increase, which results in a decrease in profits from products selling. As such, compared to Model ER, the manufacturer obtains a lower profitability from product marketing in Model EM. As regards $\pi_{m e}^{E M^{*}}>\pi_{m e}^{E R^{*}}$, this is quite intuitive because the retailer would sells its own extended warranty in Model ER, that is, $\pi_{m e}^{E R^{*}}=0$.

Subsequently, comparing the profitability in Model EM with those in Model ER, we now answer the last research question from the retailer's perspective as follows.

Proposition 4. Compared to Model ER, reselling the extended warranty provided by the manufacturer always hurts the retailer (i.e., $\pi_{r}^{E M^{*}}<\pi_{r}^{E R^{*}}$ in Figure 4) iff $k<k_{1}$; otherwise, the retailer would benefits from reselling the extended warranty.

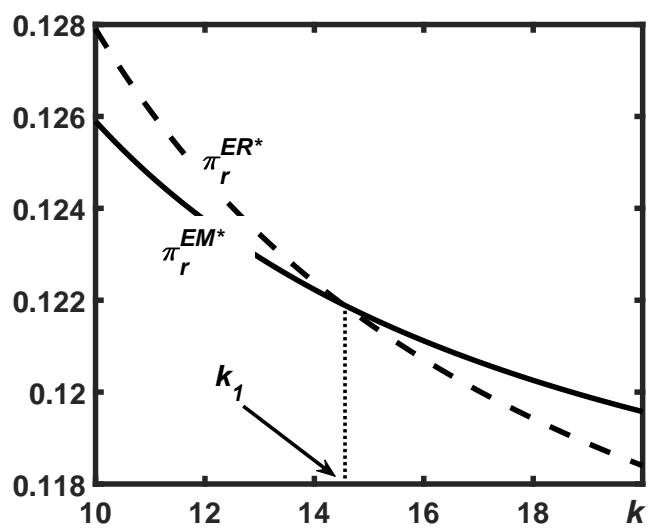

Figure 4. The retailer's profits in Model EM vs. Model ER (Note, in this example, $d=0.8, c=0.45$ ). 
Proposition 4 indicates that retailers prefers offering its own extended warranties rather than provided by a manufacturer when cost efficiency of investment on extended warranty is relatively low. This finding is constant with studies of Li et al. (2012) and Zhou et al. (2019), who shows that under certain conditions retailers can benefit from its own extended warranty. To further explain Proposition 4, like Remark 2, we reveal the variation of retailer's profitability from two different perspectives: The profitability from products and extended warranties (see, Figure 5).

Remark 3. Compared to Model ER, the retailer obtains lower profits from product and extended warranty marketing (i.e., $\pi_{r p}^{E M^{*}}<\pi_{r p}^{E R^{*}}, \pi_{r e}^{E M^{*}}<\pi_{r e}^{E R^{*}}$ in Figure 5), iff $k<k_{1}$; otherwise, the retailer would benefits more from reselling the extended warranty.

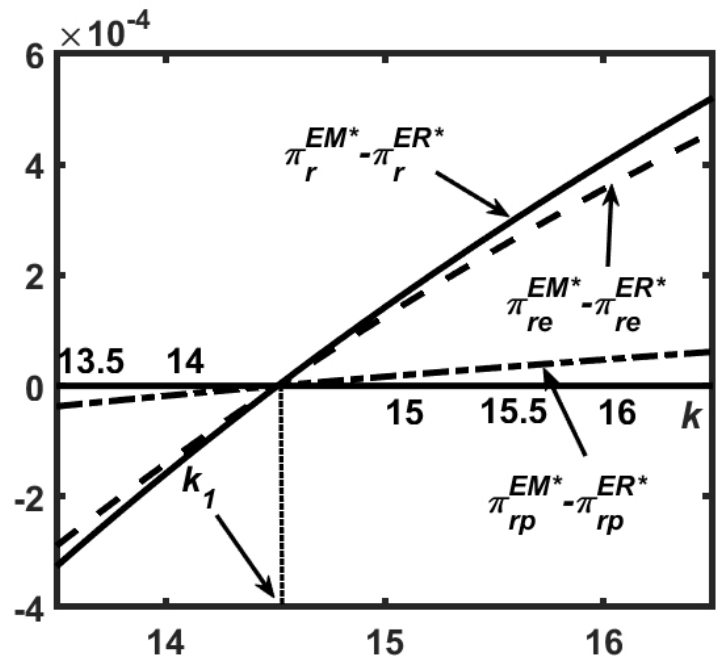

Figure 5. The retailer's profits in Model EM vs. Model ER (Note, in this example, $d=0.8, c=0.45$ )

Note that, when $k<k_{1}$, meaning selling extended warranty is a profitable business, as such, the retailer would benefit more from selling its own extended warranty than reselling the extended warranty provided by the manufacturer. Observing the retailer can expand its profit through selling extended warranty, as Proposition 1 shown, the manufacturer would charge a higher wholesale price for the product that results in the marginal revenue from selling products in the retail channel decreases. As such, when $k<k_{1}$, compared to Model ER, the retailer obtains lower profits from product marketing. When $k>k_{1}$, of course, the retailer would benefit more from Model EM than Model ER due to the following reasons. On the one hand, when $k>k_{1}$, meaning selling extended warranty is a less profitable business, as such, the retailer's profits from selling its own extended warranty decreases. On the other hand, to lead the retailer resells the extended warranty, in Model EM, the manufacturer would be reluctant to encroach into the retail market (i.e., as Proposition 1 (ii) shown, $q_{m p}^{E M^{*}}<q_{m p}^{E R^{*}}$ in Figure 1(c)), this induces a increase in retailer's profits from products and extended warranty selling.

Remark 3 reveals that the retailer may benefit more from reselling extended warranty provided by the manufacture. An argument partly supported by Jiang and Zhang (2011) who argue that from the consumer's point of view, the retailer's service plan complements (extended warranty) can even substitute for the manufacturer's base 
warranty and always increases profits for the retailer and the channel as a whole, but not necessarily for the manufacturer. A difference that we believe stems from our model's focus on a scenario where the retailer resells extended warranty under supplier encroachment.

\section{Extension}

In addition to selling products directly, some brand name manufacturers, including Apple, Dell and Huawei, today operate an online channel to provide their extended warranty as well. In the previous section we showed that, when marketing cost of the extended warranty is high, reselling extended warranties from the manufacturer results in Pareto gains for both parties. It is not clear whether such Pareto gains is robust when confronting the supplier encroachment through selling both the products and extended warranty on the direct channel. To shed light on this issue, in this section we extend the game presented in $\S 4$ to the case where the manufacturer encroaches the retail market by selling both the products and extended warranty through its own direct channel.

In this case, because consumer are allowed to purchase products and services from both channels. We can thus derive the following demand functions for extended warranty as $q_{r e}=q_{r p}-d p_{r e}+t_{r}$ and $q_{m e}=q_{m p}-d p_{m e}+t_{m}$. Because both parties competes with each other in selling both products and extended warranty, as such we assume that consumers are only allowed to buy the extended warranty in the same channel as purchasing the products.

\subsection{Model ER}

In Model ER, the manufacturer sells products and extended warranty through a direct channel, as well as an independent retailer who offers its own extended warranty. As such, the manufacturer's problem is:

$$
\underset{w_{p}, q_{m p}, p_{m e}, t_{m}}{\operatorname{Max}} \pi_{m}^{E R}=w_{p} q_{r p}+(p-c) q_{m p}+q_{m e}\left(p_{m e}-c-\frac{1}{2} k t_{m}^{2}\right)
$$

Given the manufacturer's optimal decisions, then the retailer's problem is:

$$
\underset{q_{r p}, p_{r e}, t_{r}}{\operatorname{Max}} \pi_{r}^{E R}=\left(p-w_{p}\right) q_{r p}+q_{r e}\left(p_{r e}-\frac{1}{2} k t_{r}^{2}\right)
$$

Similar to that in $\S 4$, we get equilibrium decisions and profits in Table 3, which listed in Appendix.

\subsection{Model EM}

In Model EM, the manufacturer sells products and extended warranty through a direct channel, as well as an independent retailer who resells both products and extended warranty provided by the manufacturer. As such, the manufacturer's problem is: 
Given the manufacturer's optimal decisions, then the retailer's problem is:

$$
\underset{q_{r p}, p_{r e}}{\operatorname{Max}} \pi_{r}^{E M}=\left(p-w_{p}\right) q_{r p}+q_{r e}\left(p_{r e}-w_{e}\right)
$$

Using backward induction, we get equilibrium decisions and profits in Table 3, which listed in Appendix.

Based on the outcomes in Table 3, we now can address the related research questions. Because the manufacturer sells products and extended warranty through a direct channel, we can not highlight whether it is profitable for a retailer to engage in selling extended warranties by comparing the our two models' results with Arya et al.'s (2007) encroachment setting. Like $\S 4$, we first construct the following proposition on the question of how will optimum decisions vary under different strategic choice?

Proposition 5. (i) In Model EM, the manufacturer always sets a lower wholesale price for the product than that in Model ER (i.e. $w_{p}^{E M^{*}}<w_{p}^{E R^{*}}$ );

(ii) In Model EM, the manufacturer always sells more units through the direct channel (i.e., $q_{m p}^{E M^{*}}>q_{m p}^{E R^{*}}$ ), but always makes less units available in the traditional retail channel (i.e., $q_{r p}^{E M^{*}}<q_{r p}^{E R^{*}}$ );

(iii) The extended warranty coverage of manufacturer in Model EM is larger than that of Model ER (i.e., $t_{m}^{E M^{*}}>t_{m}^{E R^{*}}$ ).

Proposition 5 (i) shows that, when the retailer reselling the extended warranty from the manufacturer, the manufacturer always sets a lower wholesale price. This can be interpreted as follows. The retailer resells both the products and the extended warranty from the manufacturer in Model EM, while in Model ER, all the extended warranty availed from the traditional channel are offered by the retailer. The manufacturer would always sets a lower wholesale price in Model EM than in Model ER in order to offset the fiercer competition from the manufacturer owned direct channel and secures the necessary outputs in traditional channel. However, Proposition 5 (ii) indicates that, to counter balance the lower wholesale price, the manufacturer would sell more products through the manufacturer-owned direct channel, which results in the retailer resells less products in Model EM than that in Model ER. Proposition 5 (iii) shows that manufacturer's extended warranty coverage in Model EM is longer than that of Model ER. Recalled that, in Model EM, the retailer resells both the products and the extended warranty from the manufacturer, meaning the manufacturer is a monopolistic supplier for offering extended warranty. Such monopolistic position results in the manufacturer with a higher incentive to promote its extended warranty by setting a longer extended warranty coverage.

Based on the outcomes in Table 3, we can construct the following proposition on the question of which strategy is more profitable for related parties, e.g., the manufacturer and retailer, to sell the retailer's own extended warranties or resell those provided by the manufacturer?

Proposition 6. The retailer prefers to Model ER, while the manufacturer would be fond of Model $E M$ (i.e., $\pi_{r}^{E M^{*}}<\pi_{r}^{E R^{*}}$ and $\pi_{m}^{E M^{*}}>\pi_{m}^{E R^{*}}$ ). 
The intuition for the manufacturer would prefer Model EM than Model ER is analyzed in $\S 4$ and is not repeated here. As regards the preference for the retailer we can interpret it as follows. Recalled that in our extension, both parties compete with each other in products and extended warranty selling. Confronting the further extrusion from the manufacturer owned direct channel, to obtain the advantage in competition, the retailer would expand its profit by selling its own extended warranty. In sum, Proposition 6 shows that the preference confliction between both parties is quite robust; it holds true irrespective of whether the manufacturer distributes its own extended warranty through the direct channel or not.

\section{Summary and Conclusions}

Due to fierce competition in the product market under conditions of supplier encroachment, many brand name retailers, including Sears, Best Buy, and Circuit City, depend on the extended warranty contracts that they sell along with the products. In practice, a large proportion of retailers sell their own extended warranty, whilst others choose to resell the extended warranty provided by upstream agents, such as Ford, General Motors, and Dell. Several questions arise naturally from these conditions. How will optimum decisions vary under different strategic choice? Is it profitable for a retailer to engage in selling extended warranties? And finally, when faced with supplier encroachment, should the retailer sell its owned extended warranties or resell those provided by the manufacturer?

In this paper, we developed two stylized theoretical models to answer the preceding questions. More specifically, we allowed for the situation where the retailer can choose to offer its own extended warranty (Model ER) or resell the extended warranty provided by manufacturer (Model EM). We compared these two models in terms of optimal outcomes and profits for the retailer and the manufacturer. This modelling has extended upon the market situation discussed by Cattani et al. (2006); Arya et al. (2007) and Cai (2010), rather than focusing on whether the supplier encroaches into retail market, we looked at the strategic response of the retailers to supplier encroachment by marketing extended warranties. Our analysis also provides an alternative, yet still complementary approach to research in the design of warranties by Desai and Padmanabhan (2004); Li et al. (2012); Heese (2012), by considering how supplier encroachment affects the optimal strategies that are available to the retailer when marketing extended warranties.

Analysis has revealed that it is indeed a profitable business for both parties when the retailer engaging in selling extended warranties irrespective of whether they are owned by the retailer or provided by the manufacturer. Furthermore, relative to selling its own extended warranties, reselling extended warranties from the manufacturer is always beneficial for the manufacturer. As regards the retailer's profits, we find that, when marketing cost of the extended warranty is high, the retailer would also prefer reselling extended warranties from the manufacturer than selling its own extended warranties. As such, reselling extended warranties from the manufacturer may result in Pareto gains for both parties. However, when marketing cost of the extended warranty is not pronounced, a preference confliction raises between both parties: The retailer prefers to sell its own extended warranty, while the manufacturer would be fond of the other one. Extending both model to the case where the manufacturer sells products and extended warranty in the direct channel, we find that the preference confliction between both parties is quite robust. 
We believe that our work remains to be pursued to extend on the following several possible research directions.

First, we modeled the extended warranty as a "after-sales service product" with price and the length of coverage, and assumed that both partners are limited to a scenario involving a linear price. Although this assumption is common in the relative literature (see, e.g., Desai and Padmanabhan (2004) and Heese (2012)), it is worth relaxed, because channel taste and quality choice are also two main reasons that consumers cite for purchasing behavior, which could offer a fruitful direction for future research.

Second, like Li et al. (2012) and Yan et al. (2017), we simplify our model into a monopoly manufacturer who acts as the Stackelberg leader. However, in reality, many powerful retailers such as Walmart, Tesco, and Carrefour, usually act as Stackelberg leader and have the first-move advantages in their supply chain. In addition, duopoly competing supply chain system and third-party competition also may be another interesting research direction. That is, future research can focus on the structure power of supply chain and multiple competitors.

Third, to focus on the impact of the extended warranty and encroachment, it is assumed that the manufacturer and retailer are complete information. However, the research can be relaxed to a more general setting in which members in supply chain are asymmetric information, specifically, where the manufacturer holds the information from direct channel but the retailer holds information from traditional market.

\section{Disclosure statement}

The authors declare no conflict of interest

\section{Funding}

The authors thank National Natural Science Foundation of China (71531003, 71872028 and 71971043), the Humanities and Social Sciences Foundation for Young Scholars of China's Ministry of Education (15YJC630154) for supporting this research.

\section{Notes on contributor(s)}

Junwu Chai contributed to model development; Hengyu Li contributed to writing; Wei Yan contributed to strengthen all results' interpretaion; Youwei Li provided motivation cases. All authors read and approved the final manuscript

\section{References}

Anderson, E. E., 1977. Product price and warranty terms: an optimization model. Journal of the Operational Research Society, 28(3), 739-741.

Arya, A., Mittendorf, B. and Sappington, D. E. M., 2007. The bright side of supplier encroachment. Marketing Science, 26(5), 651-659.

Berner 2004. The warranty windfall: Service contracts are cash cowsbut retailers are mum about their importance. Business Week, 84-86. 
Bian, Y., Xie, J., Archibald, T. W., and Sun, Y. 2019. Optimal extended warranty strategy: Offering trade-in service or not? European Journal of Operational Research, 278 (1), 240-254.

Cai, G. 2010. Channel selection and coordination in dual-channel supply chains. Journal of Retailing, 86(1), 22-36.

Cao, KY., He, P., and Liu, ZX., 2019. Production and pricing decisions in a dualchannel supply chain under remanufacturing subsidy policy and carbon tax policy. Journal of the Operational Research Society. Published online: 04 Jun 2019. Available at https://doi.org/10.1080/01605682.2019.1605471.

Cattani, K., Gilland, W., Heese, H. S., and Swaminathan, J. 2006. Abstract boiling frogs:Shan pricing strategies for a manufacturer adding a direct channel that competes with the traditional channel. Production and Operations Management, 15(1), 40-56.

Chiang, W. Y. K., Chhajed, D., and Hess, J. D. 2003. Direct marketing, indirect profits: a strategic analysis of dual-channel supply-chain design. Management Science, 49(1), 1-20.

Chu, J., and Chintagunta, P. K. 2009. Quantifying the economic value of warranties in the u.s. server market. Marketing Science, 28(1), 99-121.

Desai, P. S., and Padmanabhan, P. 2004. Durable good, extended warranty and channel coordination. Review of Marketing Science, 2(1), 2-2.

Frazier, G. L., and Lassar, W. M. 1996. Determinants of distribution intensity. Journal of Marketing, 60(4), 39-51.

Ha, A., Long, X., and Nasiry, J. 2016. Quality in supply chain encroachment. Advances in Engineering Software, $100(2), 215-230$.

Hartman, J. C., and Kamonkan, L. 2010. Designing and pricing menus of extended warranty contracts. Naval Research Logistics, 56(3), 199-214.

Heese, H. S. 2012. Retail strategies for extended warranty sales and impact on manufacturer base warranties. Decision Sciences, 43(2), 341-367.

Hollis, A. 1999. Extended warranties, adverse selection, and aftermarkets. Journal of Risk and Insurance, $66(3), 321-343$.

Jiang, B., and Zhang, X. 2011. How does a retailer's service plan affect a manufacturer's warranty?. Management Science, 57(4), 727-740.

Li, K., Mallik, S., and Chhajed, D. 2012. Design of extended warranties in supply chains under additive demand. Production and Operations Management, 21 (4), 730-746.

Li, Z., Gilbert, S. M., and Lai, G. 2014. Supplier Encroachment Under Asymmetric Information. Management Science 60(2), 449-462.

Lu, Z., and Shang, J. 2019. Warranty mechanism for pre-owned tech products: Collaboration between E-tailers and online warranty provider. International Journal of Production Economics, 211, 119-131.

Lutz, S. 1997. Vertical product differentiation and entry deterrence. Journal of Economics, $65(1), 79-102$.

Ma, J., Ai, X., Yang, W., and Pan, Y. 2019. Decentralization versus coordination in competing supply chains under retailers' extended warranties. Annals of Operations Research, $275(2)$, 485-510.

Mai, D. T., Liu, T., Morris, M. D. S., and Sun, S. 2017. Quality coordination with extended warranty for store-brand products. European Journal of Operational Research, 256(2), 524532.

Padmanabhan, V. 1995. Usage Heterogeneity and Extended Warranties. Journal of Economics and Management Strategy, 4(1), 33-53.

Patankar, J. G., and Worm, G. H. 1981. Prediction intervals for warranty reserves and cash flows. Management Science, 27(2), 237-241.

Pingle, M. 2010. Using gambling to teach insurance principles. UNR Joint Economics Working Paper Series Working Paper No. 10-006.

Tan, Y. F., Yi, Y. Y., and Yao, J. J. 2015. Supply chain coordination for strong retailer with extended warranty under network externality. Journal of Service Science and Management, $08(3), 393-409$.

Tedeschi, B. 2000. Compressed data; big companies go slowly in devising net strategy. New 
York Times, March 27.

Tsay, A. A., and Agrawal, N. 2004. Channel conflict and coordination in the e-commerce age. Production and Operations Management, 13(1), 93-110.

Xiong, Y., Wei, Y., Xiong, Z. K., and Guo, N. 2012. "bricks vs. clicks": the impact of manufacturer encroachment with a dealer leasing and selling of durable goods. European Journal of Operational Research, 217(1), 75-83.

Yan, W., Xiong, Y., Chu, J., Li, G., and Xiong, Z. 2017. Clicks versus bricks: the role of durability in marketing channel strategy of durable goods manufacturers. European Journal of Operational Research. 263(3), 909-918.

Yu, Yg., Sun, LB., Guo, XL., 2019. Dual-channel decision in a shopping complex when considering consumer channel preference. Journal of the Operational Research Society. Published online: 17 Jun 2019. Available at https://doi.org/10.1080/01605682.2019.1621221.

Zhang, R., Li, M., and Liu, B. 2019. Pricing Decisions and Provider Choice on Extended Warranty Service in Supply Chain. International Journal of Information Systems and Supply Chain Management, 12(4), 55-71.

Zheng, B., Bian, Y., Sun, Y., and Ding, H. 2018. Optimal extended warranty strategy: uniform or nonuniform pricing? International Transactions in Operational Research, 00, 1-24.

Zhou, Qin and Wang, Jingqi, 2019. Product Reliability and Extended Warranty in Supply Chains. Available at SSRN: https://ssrn.com/abstract=3430954.

\section{Online Appendix}

\section{A.Technical Analysis for Two Models}

\section{A.1. Analysis of Model ER}

In Model ER, we solve the manufacturer's profit (6) and yields $q_{m p}^{*}=\left(1-q_{r p}-c\right) / 2$. Then, substitute the $q_{m p}^{*}$ into (5) yields the retailer's problem for optimal $q_{r p}, t$ and $p_{e}$.

$$
\underset{q_{r p}, p_{e}, t}{\operatorname{Max}}\left(1-q_{r p}-q_{m p}-w_{p}\right) q_{r p}+\left(p_{e}-\frac{1}{2} k t^{2}\right)\left(q_{r p}+q_{m p}-d p_{e}+t\right)
$$

Solve the first-order condition of this formula with respect to $q_{r p}, t$ and $p_{e}$ yields three Equilibrium solutions. Then we get the Hesse matrices:

$$
H=\left[\begin{array}{ccc}
-1 & 1 / 2 & -(k t) / 2 \\
1 / 2 & -2 d & d k t+1 \\
-(k t) / 2 & d k t+1 & -\left(k\left(q_{r p}-c+6 t-2 d p_{e}+1\right)\right) / 2
\end{array}\right]
$$

Then we get first order of sequential principal minor $H_{1}=-1<0$, the second order of sequential principal minor $H_{2}=2 d-1 / 4>0$, and the third order of sequential principal minor $H_{3}=k / 8-(c k) / 8-d k+\left(k q_{r p}\right) / 8+(k t) / 4+c d k-\left(d k p_{e}\right) / 4-d k q_{r p}-$ $4 d k t+d^{2} k^{2} t^{2}+2 d^{2} k p_{e}+1<0$. After that, we use Hesse matrices to exclude other solutions and achieve our optimal solution.

$$
\begin{aligned}
& q_{r p}^{*}=-\left(d k+4 d^{2} k-8 d^{2} k w_{p}-c d k+4 c d^{2} k+1\right) /\left(-8 k d^{2}+k d\right) \\
& t^{*}=1 /(d k) \\
& p_{e}^{*}=\left(4 d^{2} k w_{p}-6 d^{2} k-12 d+2 c d^{2} k+1\right) /\left(-16 k d^{3}+2 k d^{2}\right)
\end{aligned}
$$


Plugging $q_{r p}^{*}, t^{*}$ and $p_{e}^{*}$ into the manufacturer's profit (4), we can obtain $w_{p}^{*}=$ $-\left(d k-4 d+4 d^{2} k-48 d^{3} k-c d k+4 c d^{2} k+16 c d^{3} k+1\right) /\left(16 d^{2} k(6 d-1)\right)$. Substituting $w_{p}^{*}$ into $q_{r p}, t, q_{m p}, p_{e},(5)$ and (6) to get the rest equilibrium outcomes in Model ER. We notice that all parameters and variables must satisfy nonnegativity constraints. Then, we solve the parameter scope of these nonlinear conditions:

$$
\Delta E R=\{1 / 4<d<1, \text { and } 0<c<(12 d-3) /(20 d-3), \text { and } k>1 /(d(3 c+12 d-20 c d-3))\}
$$

\section{A.2. Analysis of Model EM}

In Model EM, we solve the manufacturer's profit (9) and yields $q_{m p}^{*}=\left(1-q_{r p}-c\right) / 2$.

Then, substitute the $q_{m p}^{*}$ into (8) yields the retailer's problem for optimal $q_{r p}$ and $p_{e}$.

$$
\underset{q_{r p}, p_{e}}{\operatorname{Max}}\left(1-q_{r p}-q_{m p}-w_{p}\right) q_{r p}+\left(p_{e}-w_{e}\right)\left(q_{r p}+q_{m p}-d p_{e}+t\right)
$$

The first-order condition of this formula with respect to $q_{r p}$ and $p_{e}$ yields

$$
\begin{aligned}
& q_{r p}^{*}=\frac{8 d-2 c+4 t+2 w_{e}+8 c d-12 d w_{e}-16 d w_{p}-k t^{2}+4 d k t^{2}+2}{2(8 d-1)} \\
& p_{e}^{*}=\frac{k t^{2}-8 t+2 c+4 w_{p}-8 d w_{e}-6}{2(1-8 d)}
\end{aligned}
$$

Plugging $q_{r p}^{*}$ and $p_{e}^{*}$ into the manufacturer's profit (7) yields the retailer's problem for optimal $w_{p}, w_{e}$ and $t$.

$$
\underset{w_{p}, w_{e}, t}{M a x} w_{p} q_{r p}+\left(1-q_{r p}-q_{m p}-c\right) q_{m p}+\left(q_{r p}+q_{m p}-d p_{e}+t\right)\left(w_{e}-\frac{1}{2} k t^{2}\right)
$$

Here, we get Hesse matrices:

$$
H=\left[\begin{array}{c}
\frac{16 d(1-6 d)}{(8 d-6)^{2}} \\
\frac{80 d^{2}-24 d+2}{-2(8 d-1)^{2}} \\
\frac{16 d+2 k t+64 d^{2} k t-20 d k t-4}{2(8 d-1)^{2}}
\end{array}\right.
$$

Similar with analysis of Model ER, we achieve our optimal solution with respect to $w_{p}, w_{e}$ and $t$ yields:

$$
\begin{aligned}
& w_{p}^{*}=\frac{2 d k-6 d-14 d^{2} k+44 d^{3} k-96 d^{4} k+12 d^{2}-2 c d k+18 c d^{2} k-44 c d^{3} k+32 c d^{4} k+1}{-192 k d^{4}+64 k d^{3}-16 k d^{2}+2 k d} \\
& w_{e}^{*}=\frac{10 d+2 d^{2} k-16 d^{3} k+48 d^{4} k-48 d^{2}+144 d^{3}-2 c d^{2} k+32 c d^{3} k-112 c d^{4} k-1}{2 d^{2} k\left(96 d^{3}-32 d^{2}+8 d-1\right)} \\
& t^{*}=1 /(d k)
\end{aligned}
$$


Then we can easily show the optimal $w_{p}^{*}, w_{e}^{*}$ and $t^{*}$. Substituting $w_{p}^{*}, w_{e}^{*}$ and $t^{*}$ into $q_{r p}, q_{m p}, p_{e},(8)$ and (9) get the rest equilibrium outcomes in Model EM. We notice that all parameters and variables must satisfy nonnegativity constraints. Then, we solve the parameter scope of these nonlinear conditions:

$$
\Delta E M=\left\{\begin{array}{l}
1 / 2<d<1, \text { and } 3 d /(1+5 d)<c<\left(1-8 d+24 d^{2}\right) /\left(1-8 d+40 d^{2}\right) \\
k_{0}<k<\left(24 d^{2}-10 d+1\right) /\left(2 d^{2}\left(4 d-5 c+12 c d+80 c d^{2}-48 d^{2}+1\right)\right) \\
k_{0}=\frac{-\left(69120 d^{6}-85504 d^{5}+41024 d^{4}-11136 d^{3}+1720 d^{2}-128 d+3\right)}{8 d^{2}\left(11904 d^{5}-13376 d^{4}+6560 d^{3}-1760 d^{2}+242 d-13\right)}
\end{array}\right\}
$$

\section{B. Proofs}

\section{B.1. Proof of Proposition 1}

We let $q_{r p}^{E M^{*}}-q_{r p}^{E R^{*}}$, after simplification, we get $(4 d-1)\left(8 d-d k+8 d^{2} k-24 d^{3} k-24 d^{2}+\right.$ $\left.c d k-16 c d^{2} k+56 c d^{3} k-1\right) /\left((2 d k)(6 d-1)\left(96 d^{3}-32 d^{2}+8 d-1\right)\right)$. Solving this equation for $k$, the we get two root $k_{1}=\left(24 d^{2}-8 d+1\right) /\left(d\left(c+8 d-16 c d+56 c d^{2}-24 d^{2}-1\right)\right)$ and $k_{2}$. We proved that only $k_{1}$ is in the range of the threshold $\Delta$, and the slope of this equation with respect to $k$ is positive. Thus, if $k<k_{1}, q_{r p}^{E M^{*}}<q_{r p}^{E R^{*}}$, otherwise, if $k>k_{1}, q_{r p}^{E M^{*}}>q_{r p}^{E R^{*}}$.

We let $q_{m p}^{E M^{*}}-q_{m p}^{E R^{*}}$, after simplification, we get $\left((16 d-3)\left(d k-8 d-8 d^{2} k+24 d^{3} k+\right.\right.$ $\left.\left.24 d^{2}-c d k+16 c d^{2} k-56 c d^{3} k+1\right)\right) /\left(4 d k\left(576 d^{4}-288 d^{3}+80 d^{2}-14 d+1\right)\right)$. Solving this equation for $k$, the we get two root $k_{1}=\left(24 d^{2}-8 d+1\right) /\left(d\left(c+8 d-16 c d+56 c d^{2}-\right.\right.$ $\left.24 d^{2}-1\right)$ ) and $k_{2}$. We proved that only $k_{1}$ is in the range of the threshold $\Delta$, and the slope of this equation with respect to $k$ is positive. Thus, if $k<k_{1}, q_{m p}^{E M^{*}}>q_{m p}^{E R^{*}}$, otherwise, if $k>k_{1}, q_{m p}^{E M^{*}}<q_{m p}^{E R^{*}}$.

We let $w_{p}^{E M^{*}}-w_{p}^{E R^{*}}$, after simplification, we get $-\left(\left(40 d^{2}-12 d+1\right)\left(d k-8 d-8 d^{2} k+\right.\right.$ $\left.\left.24 d^{3} k+24 d^{2}-c d k+16 c d^{2} k-56 c d^{3} k+1\right)\right) /\left(16 d^{2} k\left(576 d^{4}-288 d^{3}+80 d^{2}-14 d+1\right)\right)$. Solving this equation for $k$, the we get two root $k_{1}=\left(24 d^{2}-8 d+1\right) /(d(c+8 d-16 c d+$ $\left.56 c d^{2}-24 d^{2}-1\right)$ ) and $k_{2}$. We proved that only $k_{1}$ is in the range of the threshold $\Delta$, and the slope of this equation with respect to $k$ is positive. Thus, if $k<k_{1}, w_{p}^{E M^{*}}<w_{p}^{E R^{*}}$, otherwise, if $k>k_{1}, w_{p}^{E M^{*}}>w_{p}^{E R^{*}}$.

\section{B.2. Proof of Proposition 2}

To prove $\pi_{r}^{E R *}>\pi_{r}^{E N *}$, we have to show that $\left(512 c^{2} d^{5} k^{2}-48 c^{2} d^{4} k^{2}-24 c^{2} d^{3} k^{2}+\right.$ $3 c^{2} d^{2} k^{2}-160 c d^{4} k^{2}+64 c d^{3} k^{2}-160 c d^{3} k-6 c d^{2} k^{2}+64 c d^{2} k-6 c d k+144 d^{4} k^{2}-40 d^{3} k^{2}+$ $\left.288 d^{3} k+3 d^{2} k^{2}-80 d^{2} k+144 d^{2}+6 d k-40 d+3\right) /\left(64 d^{3} k^{2}(6 d-1)^{2}\right)>2 c^{2} / 9$, after simplification, we have proved that in the range of the threshold $\Delta E R, \pi_{r}^{E R *}>\pi_{r}^{E N *}$ always hold.

To prove $\pi_{m}^{E R *}>\pi_{m}^{E N *}$, we have to show that $\left(112 c^{2} d^{4} k^{2}-24 c^{2} d^{3} k^{2}+c^{2} d^{2} k^{2}-\right.$ $96 c d^{4} k^{2}+32 c d^{3} k^{2}-2 c d^{2} k^{2}+16 c d^{2} k-2 c d k+48 d^{4} k^{2}-8 d^{3} k^{2}+d^{2} k^{2}+2 d k+$ 1) $/\left(32 d^{3} k^{2}(6 d-1)\right)>\left(3-6 c+7 c^{2}\right) / 12$, after simplification, we have proved that in the range of the threshold $\Delta E R, \pi_{m}^{E R *}>\pi_{m}^{E N *}$ always hold.

To prove $\pi_{r}^{E M *}>\pi_{r}^{E N *}$, we have to show that $\left(2\left(1024 c^{2} d^{6} k^{2}-120 c^{2} d^{5} k^{2}-\right.\right.$ $120 c^{2} d^{4} k^{2}+116 c^{2} d^{3} k^{2}-34 c^{2} d^{2} k^{2}+3 c^{2} d k^{2}+48 c d^{5} k^{2}-96 c d^{4} k^{2}+48 c d^{4} k-8 c d^{3} k^{2}-$ $96 c d^{3} k+10 c d^{2} k^{2}-8 c d^{2} k-c d k^{2}+10 c d k-c k+72 d^{5} k^{2}+24 d^{4} k^{2}+144 d^{4} k-4 d^{3} k^{2}+$ $\left.\left.48 d^{3} k+72 d^{3}-8 d^{2} k+24 d^{2}-4 d\right)\right) /\left(k^{2}\left(96 d^{3}-32 d^{2}+8 d-1\right)^{2}\right)>2 c^{2} / 9$, after simplification, we have proved that in the range of the threshold $\Delta E M, \pi_{r}^{E M *}>\pi_{r}^{E N *}$ always hold.

To prove $\pi_{m}^{E M^{*}}>\pi_{m}^{E N^{*}}$, after simplification, we get $\left(d k-8 d-8 d^{2} k+24 d^{3} k+24 d^{2}-\right.$ $\left.c d k+16 c d^{2} k-56 c d^{3} k+1\right)^{2} /\left(32 d^{3} k^{2}\left(576 d^{4}-288 d^{3}+80 d^{2}-14 d+1\right)\right)>0$. Thus, we 
proved that in the range of the threshold $\Delta E M, \pi_{m}^{E M^{*}}>\pi_{m}^{E N^{*}}$ always hold.

\section{B.3. Proof of Remark 1}

Notice that we explain the variation in the manufacturer's profit in Model ER, we divided manufacturer's profit, $\pi_{m}^{E R}=w_{p} q_{r p}+\left(1-q_{r p}-q_{m p}-c\right) q_{m p}$, into two parts, $\pi_{m p}^{E R}=\pi_{m}^{E R}$ represent profit of product, and $\pi_{m e}^{E R}=0$ represent profit of extended warranty. We do the similar variation in the manufacturer's profit in Model EN, and compare the outcomes between Model ER and Model EN.

To prove $\pi_{m p}^{E R^{*}}>\pi_{m p}^{E N^{*}}$, we have to show that $\left(112 c^{2} d^{4} k^{2}-24 c^{2} d^{3} k^{2}+c^{2} d^{2} k^{2}-\right.$ $96 c d^{4} k^{2}+32 c d^{3} k^{2}-2 c d^{2} k^{2}+16 c d^{2} k-2 c d k+48 d^{4} k^{2}-8 d^{3} k^{2}+d^{2} k^{2}+2 d k+$ 1) $/\left(32 d^{3} k^{2}(6 d-1)\right)>\left(3-6 c+7 c^{2}\right) / 12$, after simplification, we have proved that in the range of the threshold $\Delta E R, \pi_{m p}^{E R^{*}}>\pi_{m p}^{E N^{*}}$ always hold.

Notice that we explain the variation in the manufacturer's profit in Model EM, we divided manufacturer's profit, $\pi_{m}^{E M}=w_{p} q_{r p}+\left(1-q_{r p}-q_{m p}-c\right) q_{m p}+\left(q_{r p}+q_{m p}-d p_{e}+\right.$ $t)\left(w_{e}-\frac{1}{2} k t^{2}\right)$ into two parts, $\pi_{m p}^{E M}=w_{p} q_{r p}+\left(1-q_{r p}-q_{m p}-c\right) q_{m p}$ represent profit of product, and $\pi_{m e}^{E M}=\left(q_{r p}+q_{m p}-d p_{e}+t\right)\left(w_{e}-\frac{1}{2} k t^{2}\right)$ represent extended warranty profit in the traditional channel. We do the similar variation in the manufacturer's profit in Model EN, and compare the outcomes between Model EM and Model EN. Similar to the previous proof $\pi_{m p}^{E R^{*}}>\pi_{m p}^{E N^{*}}$, we find out $\pi_{m p}^{E M^{*}}<\pi_{m p}^{E N^{*}}$ always hold. Because of $\pi_{m e}^{E N *}=0$, without doubt $\pi_{m e}^{E M *}-\pi_{m e}^{E N *}>0$ always hold.

Notice that we explain the variation in the retailer's profit in Model ER, we divided retailer's profit, $\pi_{r}^{E R}=\left(1-q_{r p}-q_{m p}-w_{p}\right) q_{r p}+\left(p_{e}-\frac{1}{2} k t^{2}\right)\left(q_{r p}+q_{m p}-d p_{e}+t\right)$, into two parts, $\pi_{r p}^{E R}=\left(1-q_{r p}-q_{m p}-w_{p}\right) q_{r p}$ represent profit of product, and $\pi_{r e}^{E R}=$ $\left(p_{e}-\frac{1}{2} k t^{2}\right)\left(q_{r p}+q_{m p}-d p_{e}+t\right)$ represent profit of extended warranty. We do the similar variation in the retailer's profit in Model EN, and compare the outcomes between Model ER and Model EN. Because of $\pi_{r e}^{E N *}=0$, without doubt $\pi_{r e}^{E R *}-\pi_{r e}^{E N *}>0$ always hold.

To prove $\pi_{r p}^{E R^{*}}<\pi_{r p}^{E N^{*}}$, we have to show that $-\left(-256 c^{2} d^{5} k^{2}+32 c^{2} d^{4} k^{2}+8 c^{2} d^{3} k^{2}-\right.$ $c^{2} d^{2} k^{2}+32 c d^{4} k^{2}-16 c d^{3} k^{2}+32 c d^{3} k+2 c d^{2} k^{2}-16 c d^{2} k+2 c d k+8 d^{3} k^{2}-d^{2} k^{2}+16 d^{2} k-$ $2 d k+8 d-1) /\left(32 d^{3} k^{2}(6 d-1)^{2}\right)<2 c^{2} / 9$, after simplification, we have proved that in the range of the threshold $\Delta E R, \pi_{r p}^{E R^{*}}<\pi_{r p}^{E N^{*}}$ always hold.

Notice that we explain the variation in the retailer's profit in Model EM, we divided retailer's profit, $\pi_{r}^{E M}=\left(1-q_{r p}-q_{m p}-w_{p}\right) q_{r p}+\left(p_{e}-w_{e}\right)\left(q_{r p}+q_{m p}-d p_{e}+t\right)$, into two parts, $\pi_{r p}^{E M}=\left(1-q_{r p}-q_{m p}-w_{p}\right) q_{r p}$ represent profit of product, and $\pi_{r e}^{E M}=$ $\left(p_{e}-w_{e}\right)\left(q_{r p}+q_{m p}-d p_{e}+t\right)$ represent profit of extended warranty. We do the similar variation in the retailer's profit in Model EN, and compare the outcomes between Model EM and Model EN. Similar to the previous proof $\pi_{r p}^{E R^{*}}<\pi_{r p}^{E N^{*}}$, we find out $\pi_{r p}^{E M^{*}}<\pi_{r p}^{E N^{*}}$ always hold. In addition, Because of $\pi_{r e}^{E N *}=0$, without doubt $\pi_{r e}^{E M *}-$ $\pi_{r e}^{E N *}>0$ always hold.

\section{B.4. Proof of Proposition 3}

We let $\pi_{m}^{E M^{*}}-\pi_{m}^{E R^{*}}$, after simplification, we get $\left(d k-8 d-8 d^{2} k+24 d^{3} k+24 d^{2}-c d k+\right.$ $\left.16 c d^{2} k-56 c d^{3} k+1\right)^{2} /\left(32 d^{3} k^{2}\left(576 d^{4}-288 d^{3}+80 d^{2}-14 d+1\right)\right)$. After simplification, in the range of the threshold $\Delta$, we find out $\pi_{m}^{E M^{*}}>\pi_{m}^{E R^{*}}$ always hold. Here and mentioned later, $\Delta \in\{\Delta E R \cap \Delta E M\}$ represents the common area of the feasible region of the two models.

\section{B.5. Proof of Remark 2}

We explain the variation in manufacturer's profit between Model EM and Model ER, to prove $\pi_{m p}^{E M^{*}}<\pi_{m p}^{E R^{*}}$, we have to show that $\left(\left(10 d+2 d^{2} k+8 d^{3} k-96 d^{4} k-24 d^{2}-\right.\right.$ $\left.10 c d^{2} k+24 c d^{3} k+160 c d^{4} k-1\right)\left(2 d k-6 d-14 d^{2} k+56 d^{3} k-96 d^{4} k+24 d^{2}-2 c d k+22 c d^{2} k-\right.$ $\left.\left.88 c d^{3} k+160 c d^{4} k+1\right)\right) /\left(4 d^{2} k^{2}\left(96 d^{3}-32 d^{2}+8 d-1\right)^{2}\right)-\left(\left(2 d k-2 c d k+64 c d^{3} k+2\right)(2 d * k-\right.$ 
$\left.\left.6 d-14 d^{2} k+44 d^{3} k-96 d^{4} k+12 d^{2}-2 c d k+18 c d^{2} k-44 c d^{3} k+32 c d^{4} k+1\right)\right) /\left(2 d k^{2}\left(96 d^{3}-\right.\right.$ $\left.\left.32 d^{2}+8 d-1\right)^{2}\right)<\left(3 d k-12 d^{2} k-3 c d k+20 c d^{2} k+1\right)^{2} /\left(16 d^{2} k^{2}(6 d-1)^{2}\right)-((d k-c d k+$ $\left.\left.8 c d^{2} k+1\right)\left(d k-4 d+4 d^{2} k-48 d^{3} k-c d k+4 c d^{2} k+16 c d^{3} k+1\right)\right) /\left(32 d^{3} k^{2}(6 d-1)^{2}\right)$, after simplification, we have proved that in the range of the threshold $\Delta, \pi_{m p}^{E M^{*}}<\pi_{m p}^{E R^{*}}$ always hold. In addition, Because of $\pi_{m e}^{E R *}=0$, without doubt $\pi_{m e}^{E M *}-\pi_{m e}^{E R *}>0$ always hold.

\section{B.6. Proof of Proposition 4}

We let $\pi_{r}^{E M^{*}}-\pi_{r}^{E R^{*}}$, after simplification, we get $\left(2048 c^{2} d^{6} k^{2}-240 c^{2} d^{5} k^{2}-240 c^{2} d^{4} k^{2}+\right.$ $232 c^{2} d^{3} k^{2}-68 c^{2} d^{2} k^{2}+6 c^{2} d k^{2}+96 c d^{5} k^{2}-192 c d^{4} k^{2}+96 c d^{4} k-16 c d^{3} k^{2}-192 c d^{3} k+$ $20 c d^{2} k^{2}-16 c d^{2} k-2 c d k^{2}+20 c d k-2 c k+144 d^{5} k^{2}+48 d^{4} k^{2}+288 d^{4} k-8 d^{3} k^{2}+96 d^{3} k+$ $\left.144 d^{3}-16 d^{2} k+48 d^{2}-8 d\right) /\left(k^{2}\left(96 d^{3}-32 d^{2}+8 * d-1\right)^{2}\right)-\left(512 c^{2} d^{5} k^{2}-48 c^{2} d^{4} k^{2}-\right.$ $24 c^{2} d^{3} k^{2}+3 c^{2} d^{2} k^{2}-160 c d^{4} k^{2}+64 c d^{3} k^{2}-160 c d^{3} k-6 c d^{2} k^{2}+64 c d^{2} k-6 c d k+144 d^{4} k^{2}-$ $\left.40 d^{3} k^{2}+288 d^{3} k+3 d^{2} k^{2}-80 d^{2} k+144 d^{2}+6 d k-40 d+3\right) /\left(64 d^{3} k^{2}(6 d-1)^{2}\right)$. Solving this equation for $k$, the we get two root $k_{1}=\left(24 d^{2}-8 d+1\right) /\left(d\left(c+8 d-16 c d+56 c d^{2}-\right.\right.$ $\left.24 d^{2}-1\right)$ ) and $k_{2}$. We proved that only $k_{1}$ is in the range of the threshold $\Delta$, and the slope of this equation with respect to $k$ is positive. Thus, if $k<k_{1}, \pi_{r}^{E M^{*}}<\pi_{r}^{E R^{*}}$, otherwise, if $k>k_{1}, \pi_{r}^{E M^{*}}>\pi_{r}^{E R^{*}}$.

\section{B.7. Proof of Remark 3}

We explain the variation retailer's profit between Model EM and Model ER, we let $\pi_{r e}^{E M^{*}}-\pi_{r e}^{E R^{*}}$, after simplification, we get $\left(4 d\left(6 d+c k+d k+6 d^{2} k-7 c d k+10 c d^{2} k+\right.\right.$ $\left.1)^{2}\right) /\left(k^{2}\left(96 d^{3}-32 d^{2}+8 d-1\right)^{2}\right)-\left(12 d-d k+12 d^{2} k+c d k-4 c d^{2} k-1\right)^{2} /\left(64 d^{3} k^{2}(6 d-1)^{2}\right)$. Solving this equation for $k$, the we get two root $k_{1}=\left(24 d^{2}-8 d+1\right) /(d(c+8 d-16 c d+$ $\left.56 c d^{2}-24 d^{2}-1\right)$ ) and $k_{2}$. We proved that only $k_{1}$ is in the range of the threshold $\Delta$, and the slope of this equation with respect to $k$ is positive. Thus, if $k<k_{1}, \pi_{r e}^{E M^{*}}<\pi_{r e}^{E R^{*}}$, otherwise, if $k>k_{1}, \pi_{r e}^{E M^{*}}>\pi_{r e}^{E R^{*}}$.

We explain the variation retailer's profit between Model EM and Model ER, we let $\pi_{r p}^{E M^{*}}-\pi_{r p}^{E R^{*}}$, after simplification, we get $\left(-256 c^{2} d^{5} k^{2}+32 c^{2} d^{4} k^{2}+8 * c^{2} d^{3} k^{2}-c^{2} d^{2} k^{2}+\right.$ $32 c d^{4} k^{2}-16 c d^{3} k^{2}+32 c d^{3} k+2 c d^{2} k^{2}-16 c d^{2} k+2 c d k+8 d^{3} k^{2}-d^{2} k^{2}+16 d^{2} k-2 d k+8 d-$ 1) $/\left(32 d^{3} k^{2}(6 d-1)^{2}\right)-\left(-2048 c^{2} d^{6} k^{2}+640 c^{2} d^{5} k^{2}-320 c^{2} d^{4} k^{2}+44 c^{2} d^{3} k^{2}+12 c^{2} d^{2} k^{2}-\right.$ $2 c^{2} d k^{2}+384 c d^{5} k^{2}-64 c d^{4} k^{2}+384 c d^{4} k+8 c d^{3} k^{2}-64 c d^{3} k-12 c d^{2} k^{2}+8 c d^{2} k+2 c d k^{2}-$ $\left.12 * c d k+2 c k+12 d^{3} k^{2}+24 d^{2} k+12 d\right) /\left(k^{2}\left(96 d^{3}-32 d^{2}+8 d-1\right)^{2}\right)$. Solving this equation for $k$, the we get two root $k_{1}=\left(24 d^{2}-8 d+1\right) /\left(d\left(c+8 d-16 c d+56 c d^{2}-24 d^{2}-1\right)\right)$ and $k_{2}$. We proved that only $k_{1}$ is in the range of the threshold $\Delta$, and the slope of this equation with respect to $k$ is positive. Thus, if $k<k_{1}, \pi_{r p}^{E M^{*}}<\pi_{r p}^{E R^{*}}$, otherwise, if $k>k_{1}, \pi_{r p}^{E M^{*}}>\pi_{r p}^{E R^{*}}$.

\section{B.8. Analysis of Extension}

In the extension, extended warranties are sold in both retail and direct channel. The demand function of extended warranty is $q_{r e}=q_{r p}-d p_{r e}+t_{r}$ and $q_{m e}=q_{m p}-d p_{m e}+$ $t_{m}$, respectively. In Model ER, the manufacturer will chooses its optimal outputs of products $\left(q_{m p}\right)$, the price of its own extended warranty $\left(p_{e}\right)$ and the extended warranty length $\left(t_{m}\right)$ to maximise its profits $\pi_{m}^{E R}=w_{p} q_{r p}+\left(1-q_{r p}-q_{m p}-c\right) q_{m p}+\left(q_{m p}-d p_{m} e+\right.$ $\left.t_{m}\right)\left(p_{m e}-c-\frac{1}{2} k t_{m}^{2}\right)$. Similar to the analysis of Model ER in Proof A. We use Hessian Matrix to exclude the other extremum. We get $q_{m p}^{E R}=-\left(4 d^{2} k-6 c d^{2} k-4 d^{2} k q r p+\right.$ $1) /\left(-8 k d^{2}+2 k d\right), p_{m e}^{E R}=\left(6 d+2 d^{2} k-4 c d^{2} k+4 c d^{3} k-2 d^{2} k q r p-1\right) /\left(2 d^{2} k(4 d-1)\right)$ and $t_{m}^{E R}=1 /(d k)$. Substituting these into retailer's profit function $\pi_{r}^{E R}=\left(1-q_{r p}-q_{m p}-\right.$ $\left.w_{p}\right) q_{r p}+\left(q_{r p}-d p_{r e}+t_{r}\right)\left(p_{r e}-\frac{1}{2} k t_{r}^{2}\right)$ and solving the FOCs with respect to $p_{r e}, q_{r p}$ and $t_{r}$. By analysis the Hessian Matrix, we get $q_{r p}^{E R}=\left(2 d-4 d^{2} k+8 d^{3} k+4 d^{2} k w_{p}-\right.$ $\left.16 d^{3} k w_{p}+12 c d^{3} k-1\right) /\left(16 k d^{3}-16 k d^{2}+2 k d\right), p_{r e}^{E R}=\left(4 d^{3} k-2 d^{2} k-11 d+12 d^{2}+\right.$ $\left.2 d^{2} k w r-8 d^{3} k w r+6 c d^{3} k+1\right) /\left(16 k d^{4}-16 k d^{3}+2 k d^{2}\right)$ and $t_{m}^{E R}=1 /(d k)$. In the last 
Table 3. Equilibrium Decisions and Profits of Extension

stage, substituting these into manufacturer's profit function again and solve the FOCs with respect to $w_{p}$ and we can determine all the solution in the following Table.

In Model EM, the manufacturer will chooses its optimal outputs of products $\left(q_{m p}\right)$, the price of its own extended warranty $\left(p_{e}\right)$ to maximise its profits $\pi_{m}^{E M}=w_{p} q_{r p}+(1-$ $\left.q_{r p}-q_{m p}-c\right) q_{m p}+\left(q_{m p}-d p_{m} e+t_{m}\right)\left(p_{m e}-c-\frac{1}{2} k t_{m}^{2}\right)+\left(q_{r p}-d p_{r} e+t_{m}\right)\left(w_{e}-\frac{1}{2} k t_{m}^{2}\right)$. We get $q_{m p}^{E M}=-\left(d k t_{m}^{2}-2 t_{m}-4 d+6 c d+4 d q_{r p}\right) /(2(4 d-1))$ and $p_{m e}^{E M}=\left(4 t_{m}-\right.$ $\left.2 q_{r p}-4 c+4 c d-k t_{m}^{2}+2 d k t_{m}^{2}+2\right) /(2(4 d-1))$. Substituting these into retailer's profit function $\pi_{r}^{E M}=\left(1-q_{r p}-q_{m p}-w_{p}\right) q_{r p}+\left(q_{r p}-d p_{r e}+t_{m}\right)\left(p_{r e}-w_{e}\right)$ and solving the FOCs with respect to $p_{r e}$ and $q_{r p}$. We get $q_{r p}^{E M}=\left(2 d t_{m}-t_{m}-2 d+d w_{e}+2 d w_{p}+\right.$ $\left.6 c d^{2}-4 d^{2} w_{e}-8 d^{2} w_{p}+4 d^{2}+d^{2} k t_{m}^{2}\right) /\left(8 d^{2}-8 d+1\right), p_{r e}^{E M}=\left(4 * d-6 t_{m}+2 w_{e}+2 w_{p}+\right.$ $\left.6 c d+8 d t_{m}-12 d w_{e}-8 d w_{p}+8 d^{2} w_{e}+d k t_{m}^{2}-2\right) /\left(2\left(8 d^{2}-8 d+1\right)\right)$. In the last stage, substituting these into manufacturer's profit function again and solve the FOCs with respect to $w_{p}, w_{e}$ and $t_{m}$. Then, we can determine all the solution in the following Table.

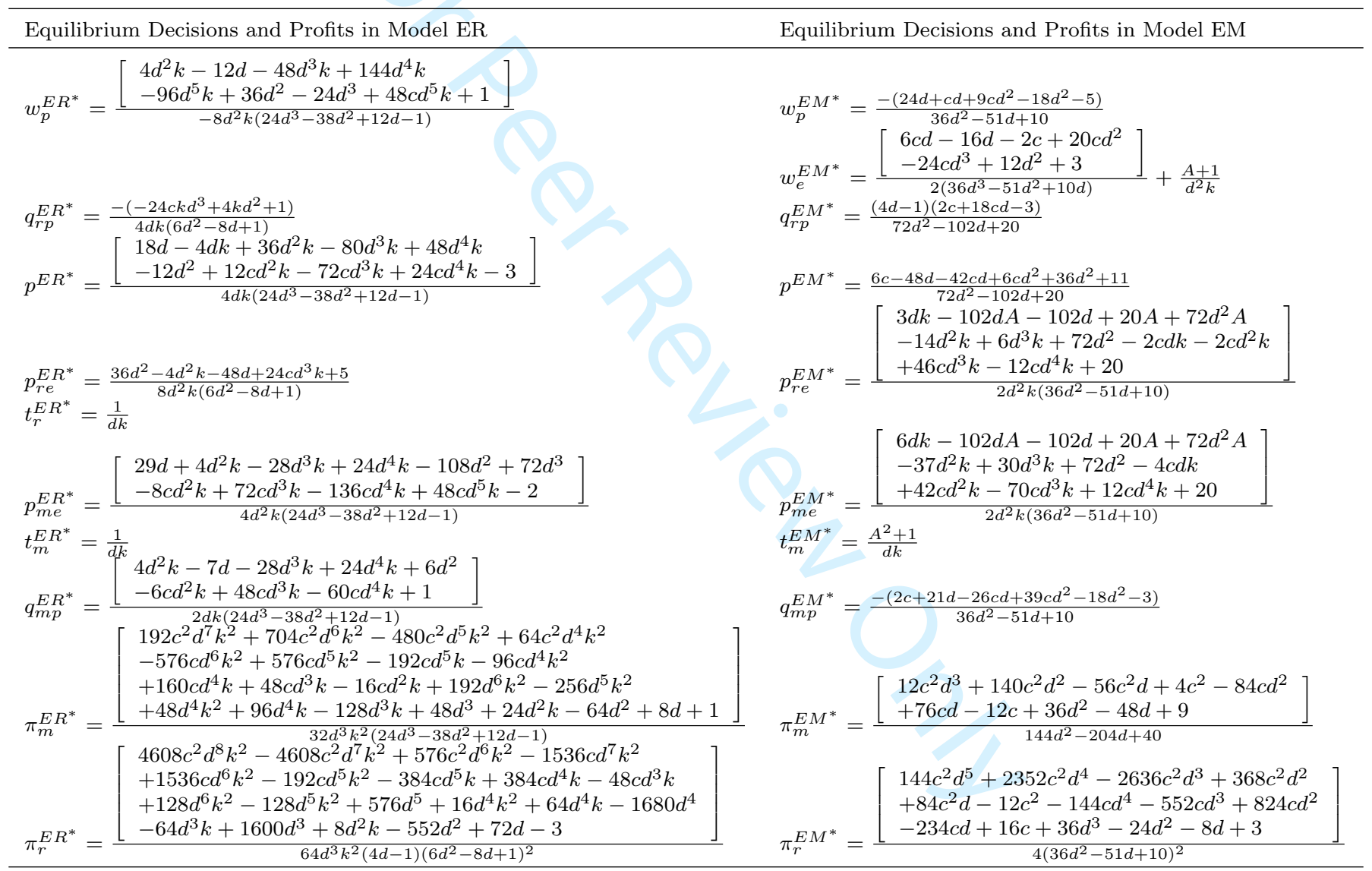

Note that $A=\sqrt{\left(6 d k-51 d-32 d^{2} k+24 d^{3} k+36 d^{2}-4 c d k+12 c d^{2} k+40 c d^{3} k-48 c d^{4} k+10\right) /\left(36 d^{2}-51 d+10\right)}$.

\section{B.9. Proof of Proposition 5}

We let $q_{r p}^{E M^{*}}-q_{r p}^{E R^{*}}$, after simplification, we get $((4 d-1)(2 c+18 c d-3)) /\left(72 d^{2}-\right.$ $102 d+20)+\left(-24 c k d^{3}+4 k d^{2}+1\right) /\left(4 d k\left(6 d^{2}-8 d+1\right)\right)$. we have proved that in the range of the threshold $\Delta, q_{r p}^{E M^{*}}<q_{r p}^{E R^{*}}$ always hold.

We let $q_{m p}^{E M^{*}}-q_{m p}^{E R^{*}}$, after simplification, we get $-\left(\left(6 d^{2}-7 d+1\right)(6 d k-51 d-\right.$ $\left.\left.32 d^{2} k+24 d^{3} k+36 d^{2}-4 c d k+12 c d^{2} k+40 c d^{3} k-48 c d^{4} k+10\right)\right) /\left(2 d k\left(864 d^{5}-2592 d^{4}+\right.\right.$ 
$\left.\left.2610 d^{3}-1028 d^{2}+171 d-10\right)\right)$. we have proved that in the range of the threshold $\Delta$, $q_{r p}^{E M^{*}}>q_{r p}^{E R^{*}}$ always hold.

We let $w_{p}^{E M^{*}}-w_{p}^{E R^{*}}$, after simplification, we get $\left(4 * d^{2} k-12 d-48 d^{3} k+144 d^{4} k-\right.$ $\left.96 d^{5} k+36 d^{2}-24 d^{3}+48 c d^{5} k+1\right) /\left(8 d^{2} k\left(24 d^{3}-38 d^{2}+12 d-1\right)\right)-\left(24 d+c d+9 c d^{2}-\right.$ $\left.18 d^{2}-5\right) /\left(36 d^{2}-51 d+10\right)$. we have proved that in the range of the threshold $\Delta$, $w_{p}^{E M^{*}}<w_{p}^{E R^{*}}$ always hold.

\section{B.10. Proof of Proposition 6}

We let $\pi_{r}^{E M^{*}}-\pi_{r}^{E R^{*}}$, after simplification, we get $\left(144 c^{2} d^{5}+2352 c^{2} d^{4}-2636 c^{2} d^{3}+\right.$ $368 c^{2} d^{2}+84 c^{2} d-12 c^{2}-144 c d^{4}-552 c d^{3}+824 c d^{2}-234 c d+16 c+36 d^{3}-24 d^{2}-$ $8 d+3) /\left(4\left(36 d^{2}-51 d+10\right)^{2}\right)-\left(4608 c^{2} d^{8} k^{2}-4608 c^{2} d^{7} k^{2}+576 c^{2} d^{6} k^{2}-1536 c d^{7} k^{2}+\right.$ $1536 c d^{6} k^{2}-192 c d^{5} k^{2}-384 c d^{5} k+384 c d^{4} k-48 c d^{3} k+128 d^{6} k^{2}-128 d^{5} k^{2}+576 d^{5}+$ $\left.16 d^{4} k^{2}+64 d^{4} k-1680 d^{4}-64 d^{3} k+1600 d^{3}+8 d^{2} k-552 d^{2}+72 d-3\right) /\left(64 d^{3} k^{2}(4 d-\right.$ 1) $\left.\left(6 d^{2}-8 d+1\right)^{2}\right)$. we have proved that in the range of the threshold $\Delta, \pi_{r}^{E M^{*}}<\pi_{r}^{E R^{*}}$ always hold.

We let $\pi_{m}^{E M^{*}}-\pi_{m}^{E R^{*}}$, after simplification, we get $\left(12 c^{2} d^{3}+140 c^{2} d^{2}-56 c^{2} d+4 c^{2}-\right.$ $\left.84 c d^{2}+76 c d-12 c+36 d^{2}-48 d+9\right) /\left(144 d^{2}-204 d+40\right)-\left(192 c^{2} d^{7} k^{2}+704 c^{2} d^{6} k^{2}-\right.$ $480 c^{2} d^{5} k^{2}+64 c^{2} d^{4} k^{2}-576 c d^{6} k^{2}+576 c d^{5} k^{2}-192 c d^{5} k-96 c d^{4} k^{2}+160 c d^{4} k+48 c d^{3} k-$ $16 c d^{2} k+192 d^{6} k^{2}-256 d^{5} k^{2}+48 d^{4} k^{2}+96 d^{4} k-128 d^{3} k+48 d^{3}+24 d^{2} k-64 d^{2}+8 d+$ 1) $/\left(32 d^{3} k^{2}\left(24 d^{3}-38 d^{2}+12 d-1\right)\right)$. we have proved that in the range of the threshold $\Delta, \pi_{m}^{E M^{*}}>\pi_{m}^{E R^{*}}$ always hold. 